\begin{tabular}{|c|c|}
\hline 2. ECN Category & one) \\
\hline Supplemental & \\
\hline Direct Revision & \\
\hline Change ECN & \\
\hline Temporary & \\
\hline Standby & \\
\hline Supersedure & \\
\hline CancelNoid & \\
\hline 12a. Modification & \\
\hline$\bigcirc$ Yes (fill out & \\
\hline O No $\underset{12 \mathrm{NA}, 1}{\mathrm{Na}}$ & \\
\hline
\end{tabular}

13a. Description of Change HNF-SD-FF-DP-008, by replacing with Revision 6 .

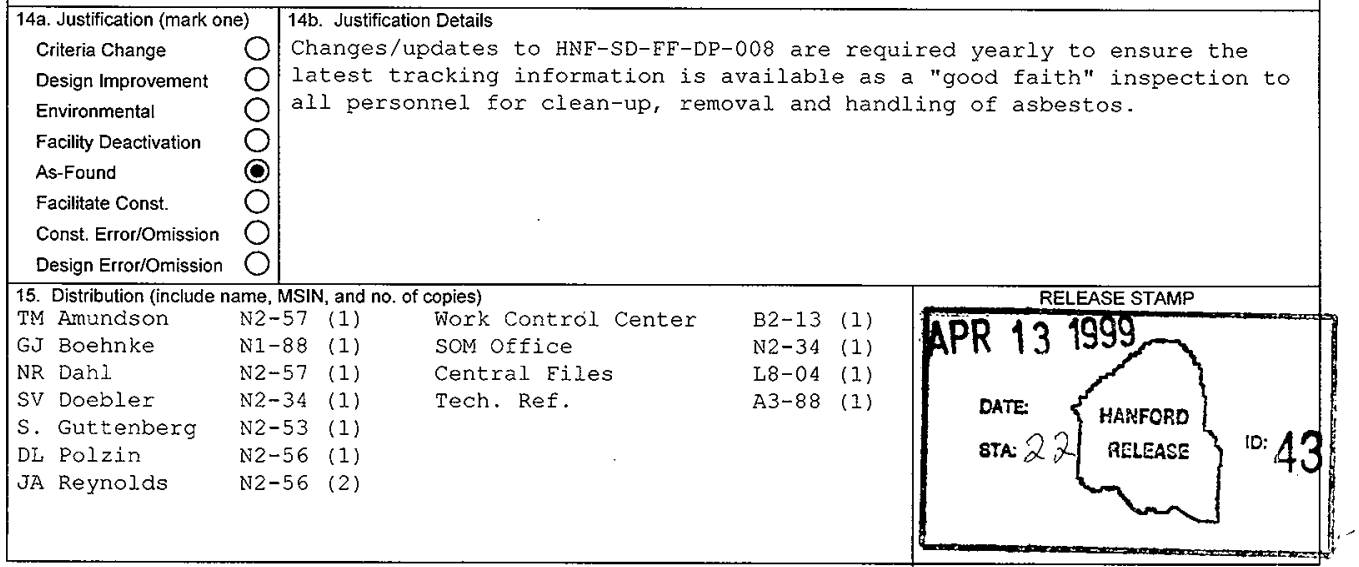


16. Design Verification Required
OYes
ONo

17. Cost Impact

ENGINEERING

Additional $\bigcirc \$$

Savings $\bigcirc \$$

\section{CONSTRUCTION}

Additional $\bigcirc \$$

Savings $\bigcirc \$$
652394

18. Schedule Impact (days)

Improvement

Delay

19. Change Impact Review: Indicate the related documents (other than the engineering documents identified on Side 1) that will be affected by the change described in Block 13. Enter the affected document number in Block 20.

SDD/DD

Functional Design Criteria

Operating Specification

Criticality Specification

Conceptual Design Report

Equipment Spec.

Const. Spec.

Procurement Spec.

Vendor Information

OM Manual

FSAR/SAR

Safety Equipment List

Radiation Work Permit

Environmental Impact Statement

Environmental Report

Environmental Permit

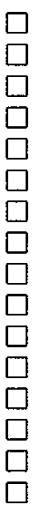

Seismic/Stress Analysis

Stress/Design Report

Interface Control Drawing

Calibration Procedure

Installation Procedure

Maintenance Procedure

Engineering Procedure

Operating Instruction

Operating Procedure

Operational Safety Requirement

IEFD Drawing

Cell Arrangement Drawing

Essential Material Specification

Fac. Proc. Samp. Schedule

Inspection Plan

Inventory Adjustment Request

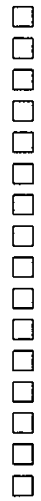

Tank Calibration Manual

Health Physics Procedure

Spares Multiple Unit Listing

Test Procedures/Specification

Component Index

ASME Coded ltem

Human Factor Consideration

Computer Software

Electric Circuit Schedule

ICRS Procedure

Process Control Manual/Plan

Process Flow Chart

Purchase Requisition

Tickler File

20. Other Affected Documents: (NOTE: Documents listed below will not be revised by this ECN.) Signatures below indicate that the signing organization has been notified of other affected documents listed below.

\section{Approvals}

Signature

Design Authority

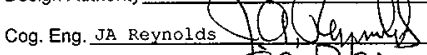
Cog. Mgr. DL Polzin

QA

\section{Safety}

Environ.

Other
Date
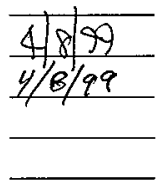

Signature

Date

Design Agent

PE

QA

Safety

Design

Environ.

\section{$4 / 9 / 98$ Other}

\section{DEPARTMENT OF ENERGY}

Signature or a Control Number that tracks the Approval Signature

\section{ADDITIONAL}




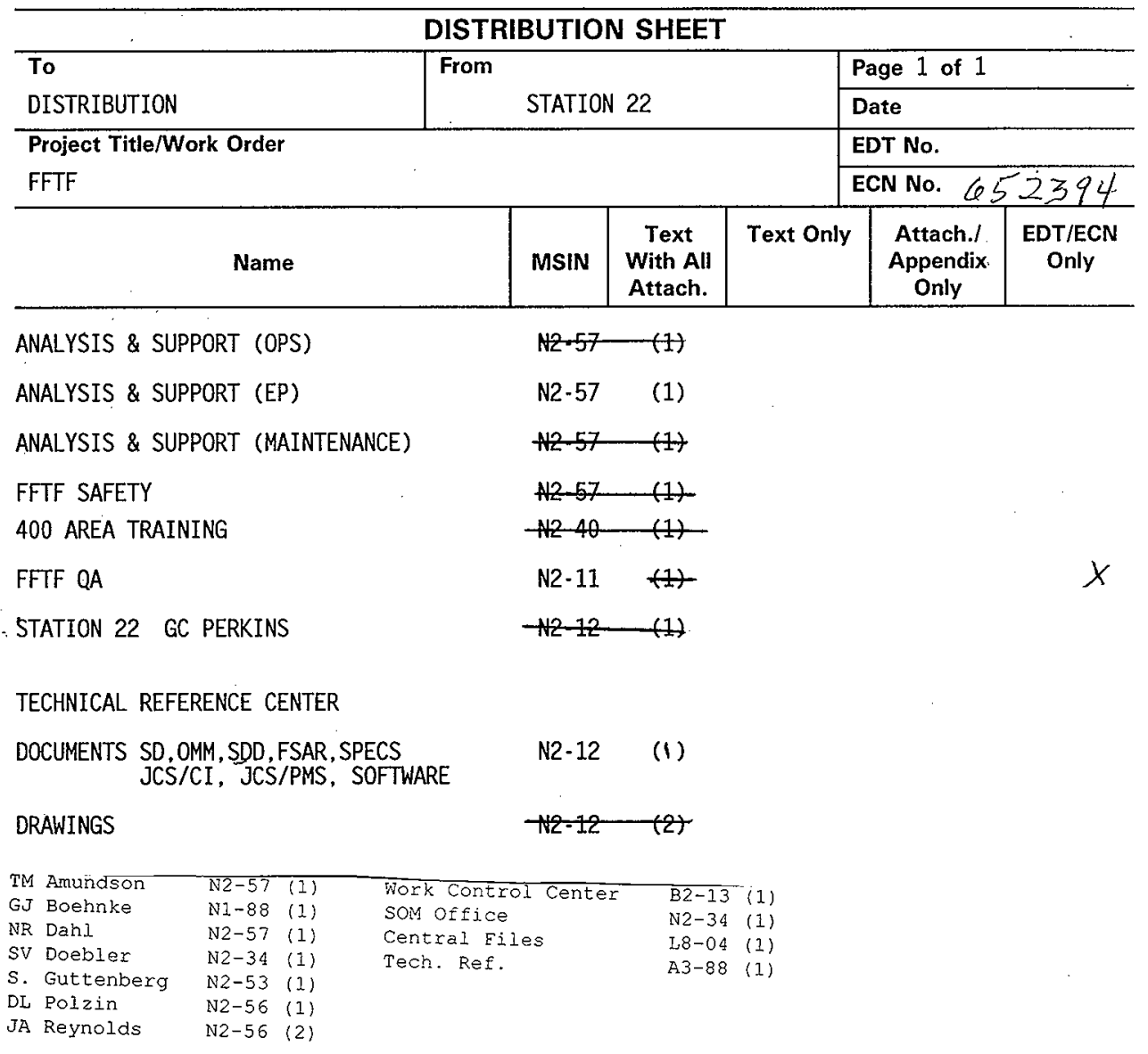




\title{
FAST FLUX TEST FACILITY ASBESTOS LOCATION TRACKING PROGRAM
}

\author{
J. A. Reynolds
}

B\&W Hanford Company

Richland, WA 99352

U.S. Department of Energy Contract DE-AC06-96RL13200

\author{
EDT/ECN: 652394 \\ UC: 900 \\ Org Code: 18200 \\ Charge Code: 101587 \\ B\&R Code: $\quad$ EX04J1020 \\ Total Pages: 30 \\ Key Words: Asbestos, Tracking, Good Faith
}

Abstract: This document updates the location and condition of asbestos found at the 400 Area East Flux Test Facility site.

TRADEMARK DISCLAIMER. Reference herein to any specific commercial product, process, or service by trade name trademark, manufacturer, or otherwise, does not necessarily constitute or imply its endorsement, recommendation, or favoring by the United States Government or any agency thereof or its contractors or subcontractors.

Printed in the United States of America. To obtain copies of this document, contact: Document Control Services, P.O. Box 950, Mailstop H6-08, Richland WA 99352, Phone (509) 372-2420; Fax (509) 376-4989.

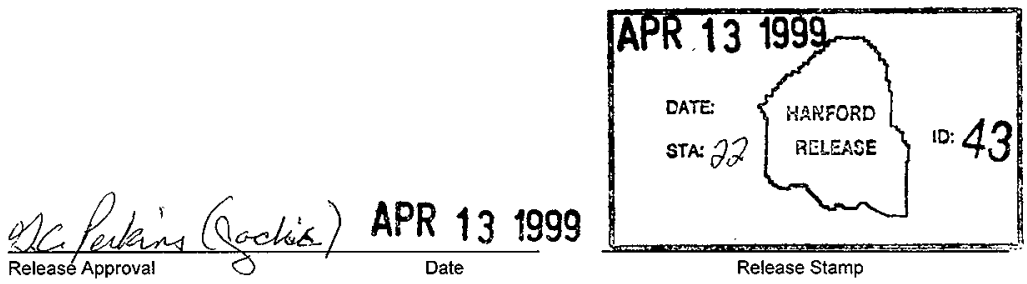

\section{Approved For Public Release}




\section{INFORMATION CLEARANCE FORM}

\begin{tabular}{|c|c|c|c|c|c|c|}
\hline \multicolumn{2}{|c|}{ A. Informatlon Category } & \multicolumn{5}{|c|}{ 8. Document Number HNE-SD-FE-DP-008, Revision 6} \\
\hline$\square$ Abstract & [] Joumal Article & c. Tute & & $\overline{7}$ & & \\
\hline$\square$ summary & $\square$ intarnet & FFTE Asbestos & Location & Tracking & Program & \\
\hline$\square$ Visuel Aid & [] Sotware & & & & & \\
\hline$\square$ Full Papet & D Report & $\cdot$ & & & & . \\
\hline \multicolumn{2}{|c|}{ 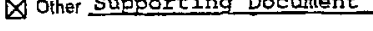 } & \multicolumn{5}{|l|}{ D. Internet Address } \\
\hline
\end{tabular}

\section{E. Required Information}

1. Is document potentially classified? $O$ No $O$ Yes (MANDATORY) Q L P Managat's Signature Required

If Yes ADC Signatura Required

2. Intemal Review Required? if Yes, Document Signatures Bolow

Ono Ores clessified Counsel

Program

3. References in the information are Apptied Technology $O$ No OYes Export Controlled Information Ono Ores
4. Does informatlon contain the Following: (MANDATORY)
a. New or Novel (Patentablo) Subjact Matter?
Ona OYes

If "Yas", Disclosure No.:

b. Information Recelved in Confidence, Such as Proprletary and/or Inventlons?

ONo OYes if "Yes", Affix Appropriate Legends/Notices.

c. copyrights? $\mathrm{O}$ No $\mathrm{O}$ Yes "Yos", Attach Permisston.

d. Tradomarks? ONo OYes "Yos", Idenuly in Document.

5. Io Informatton requlring submission to OSTI? $O$ No $O$ Yes If Yes UC- 900 and BER-EXOAJ1020

6. Release Level? $\bigcirc$ Public $O$ Limited

7. Charge Code 101587

\section{F. Complete for a Joumal Article}

4. Title of Journal

\section{G. Complete for a Presentation}

1. Title for Conference or Meeting

2. Group Sponsoring

3. Date of Conference

5. Will Informaton be Published in Proceedings? $O$ No $O$ Yes

4. City/state

H. Author/Requestor Responsible Manager

JA Reynolds

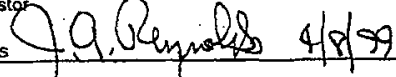
$\frac{\text { DI Polzin }}{\text { (Print and sign) }}$

(Print and Sign)

$\begin{array}{ll}\text { 1. Reviewers } & \text { Yes Print } \\ \text { General Counsel } & \square \\ \text { Office of Externa! Affairs } \square \\ \text { DoE-RL } \\ \text { Other } \\ \text { Other }\end{array}$

K. It Additonal Comments, Please Allach Separate Sheet 


\section{RELEASE AUTHORIZATION}

Document.

Number:

HNF-SD-FF-DP-008

Document

Title:

FFTF ASBESTOS LOCATION TRACKING PROGRAM

This document, reviewed in accordance with DOE Order 241.1, "Scientific and Technical Information Management," and DOE 241.1-G "Guide to the Management of Scientific and Technical Information," does not contain classified or sensitive unclassified information and is:

APPROVED FOR PUBLIC RELEASE

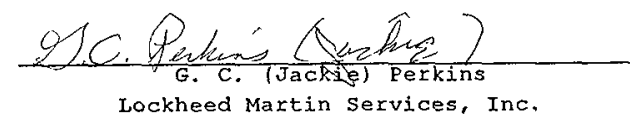

APR 131999

Reviewed for Applied Iochnology, Business Sensitive, Classified, Copyrighted, Export Controlled, Patent, Personal/ptivato, Propr hotacy, Protocted CRADA, Tisdomark, Unelassifiod controlied Nucloar information.

LEGAL DISCLAIRER. Thls report was prepared os an account of work sponsored by an agency of the Unjted States Gover hmant. Weithor the United states Government nor any sgency theroof, not any of thelr enployes, nor any of the it contractors.

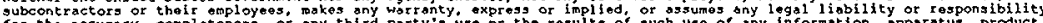
for the accuracy, complateness, or ony third party's use or the resuts of such use of any information, opporatus, product,

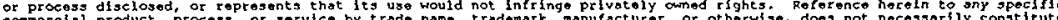
or imoly its endorgenent, reconmendation, or favoring by the United states Government or any agency theroof or its or limgly le prof of the Unitod states Governtant or any agency thereof. This report has beoin reproduced from the best avallable copy. Printed in the United States of Amerlcs. Avaliable to the U.S. Department of Energy and It 3 cont ractors from the U.S. Departmont of Bnergy office of Scientific and Technical inforation, P.O. Box 62, Ook Riggo, TN 37931; Telophone: 123/576-6801.

Avaliable to the public from the U.S. Department of Comerce National Technical Information Service, S2as port Royal Road, Apringfleld, VA 22161; Tolephone: 703487-4650. 


\section{RECORD OF REVISION}

(2) Title

FETF ASBESTOS LOCATION TRACKING PROGRAM

Change Control Record

(3) Revision

(4) Description of Change - Replace, Add, and Delete Pages

(7)

$0 \quad$ Initial release EDT 108828

$1 \quad$ Revised per ECN 703853, all pages update to Revision 1 with latest information.

2 Revised per ECN 617608, all pages update to Revision 2 with latest information.

3 Revised per ECN 627272, all pages update to Revision 3 with latest information.

4 Revised per ECN 639819, all pages update to Revision 4 with latest information.

5 Revised per ECN 639823, all pages update to Revision 5 with latest information.

6
Revised per ECN 652394, all pages update to Revision 6 with latest information.
Authorized for Release

\begin{tabular}{l|ll} 
(5) Cog. Engr. & (6) Cog. Mgr. Date
\end{tabular}

BR Bowman CG McCargar

JA Reynolds CG McCargar

JA Reynolds CG MCCargar

JA Reynolds CG McCargar

JA Reynolds CG McCargar

JA Reynolds DL Polzin

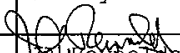

ina neyrords $4-8-89$
DL Polzin

O.SPein $4-8-99$ 


\section{TABLE OF CONTENTS}

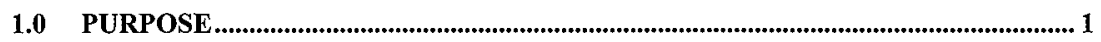

2.0 SCOPE .................................................................................................................................... 1

3.0 INSPECTION PROGRAM.............................................................................................. 1

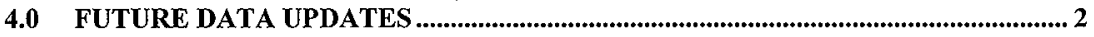

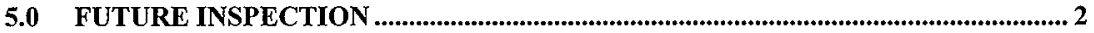

6.0 FUTURE MATERIAL/INSULATION INSTALLATION ............................................. 2

APPENDIX A: SUSPECT ACBM LOCATION SAMPLING …............................................ 3 APPENDIX B: CURRENT IDENTIFIED ACBM LOCATIONS AND BUTLDINGS ........ 16 APPENDIX C: CURRENT IDENTIFIED FRIABLE ACBM LOCATIONS BY

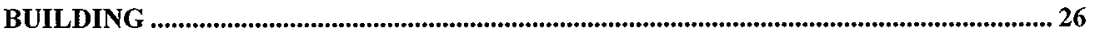


HNF-SD-FF-DP-008

Revision 6

Page 1 of 26

\subsection{PURPOSE}

Procedure Number HNF-PRO-408, revision 0, paragraph 1.0, "Purpose," and paragraph 2.0, "Requirements for Facility Management of Asbestos," relate building inspection and requirements for documentation of existing asbestos-containing building material (ACBM) per each building assessment. This documentation shall be available to all personnel (including contractor personnel) entering the facility at their request. Corrective action was required by 400 Area Integrated Annual Appraisal/Audit for Fiscal Year 1992 (IAA-92-0007) to provide this notification documentation. No formal method had been developed to communicate the location and nature of ACBM to maintenance personnel in the Fast Flux Test Facility (FFTF) 400 Area.

\subsection{SCOPE}

The scope of this Data Package Document is to locate and evaluate any ACBM found at FFTF which constitutes a baseline. This includes all buildings within the protected area. These findings are compiled from earlier reports, numerous work packages and engineering evaluations of employee findings.

\subsection{INSPECTION PROGRAM}

The inspection baseline program was generated by work package F2-902/A to locate, inspect, $\log$, test and finalize into a working document all ACBM findings during the period, October 1992 to February 1993. As possible ACBM locations were found, they were investigated visually and samples taken if suspected by the Engineering Asbestos Representative by an Asbestos Hazard Emergency Response Act Building Inspector. These samples were logged, pictures taken of the sample location and numbered (see Appendix A). The representative pictures are provided in two reference binders; one maintained by the FFTF Engineering Asbestos Engineer and one by Operations Regulatory Compliance. Samples were taken to Waste Sampling and Characterization Facility, 600 Area, and tested for contents using the Polarized Light Microscopy and Dispersion Staining methods in accordance with $40 \mathrm{CFR}$ Chapter I (7-1-93 Ed.) Part 763, Appendix E to Subpart E. For the retention period of all inspection results, see HNF-PRO-408, paragraph 2.0, subparagraph 5.

Appendix B is the location of ACBM listed by building number to simplify the task of finding possible asbestos locations.

In a few instances, $A C B M$ findings documented to a specific location in Appendix $B$, are generic deficiencies, such as cable tray insulation. In these cases, work on and inspection of this type of equipment requires ACBM controls found in any/all plant location. 
As normally inaccessible cells are opened per Operations Administrations Procedure A-16, inspections or air samples will be taken for airborne fiber content for an initial baseline inspection performed and documented per HNF-PRO-408, paragraph 2.0, subparagraph 5.

Appendix $\mathrm{C}$ lists the potential friable asbestos locations by building number and shall be inspected yearly.

\subsection{FUTURE DATA UPDATES}

FFTF Asbestos Engineering updates to this document will be made yearly by change revision. These changes will incorporate any new finding and sample results from continuing investigations through work packages, etc. When Appendices A, B and C are updated, similar revisions must be made to PMP 21A-M01.

\subsection{FUTURE INSPECTION}

Inspection of known friable locations and areas where heavy traffic or weather conditions may deteriorate insulation around piping or equipment will be performed once per year (see Appendix C). All known ACBM locations will be inspected every three years, along with the once a year inspection, per Appendix A and B. These inspections will be performed by the Preventive Maintenance Procedure, PMP 21-A-M01, "Inspection of Asbestos-Containing Building Material (ACBM)."

\subsection{FUTURE MATERIAL/INSULATION INSTALLATION}

All material and/or insulation that is installed in the facility shall be asbestos free if at all possible. If an ACBM or other asbestos containing material is used within the boundaries of this document, it will be reported to the Engineering Asbestos Engineer for documentation. 
HNF-SD-FF-DP-008

Revision 6

Appendix A

Page 3 of 26

\section{APPENDIX A: SUSPECT ACBM LOCATION SAMPLING}

\section{General Notes}

1. Asbestos-containing building materials (ACBM) (one percent or more asbestos) are warning tagged/stickered or painted pink. Pink coating may be overlaid with a white insulation outer layer.

2. Samples that have been taken from either the East, West or South Dump Heat Exchanger (DHX) will be present in the other two DHX buildings.

Reference: Gaskets located behind windows and lamp mounts or between access plates and different structure modules.

3. Wiring in cable trays that have been coated with $A C B M$ are shown in two Picture/ Locations (room 108, Picture/Location 93 and room 365, Picture/Location 143). All other cable trays located through the plant with sprayed on material must be treated as ACBM.

4. Floor tiles are sampled per color. Match the color in the Picture/Location to the existing tile. All rooms and hall are not identified in this report. See Picture/Location numbers $50,130,135,144,153,158,160,161$, and 163 .

NOTE: Positive floor tiles and/or ceiling tiles are not marked as ACBM. All floor tiles in the main Fast Flux Test Facility (FFTF) building where suspected to have asbestos in them or their adhesive, have been overlaid.

5. Gaskets that contain asbestos and that are located in closed cells are not identified by Picture/Location number (reference Picture/Location 152 of cell entrance, for Connector Box Seals, H-4-16067, in cell 489). Other gaskets in closed cells are listed on H-4-16067.

6. Adverse Insulated Cable (yellow painted wire, TM 1, and white wire, Q12) as shown in Picture/Location 149 for yellow and 148 for white are located throughout the plant.

These cables are mainly used for heat trace.

NOTE: Inner layer of material on both wires is ACBM.

7. Black Mastic coating on piping, tanks, and ductwork, usually located outside, is ACBM. Specific Picture/Location 1-16, 27, 36, 45, 47, 48, 63, 64, 65, 69, 71, 102, 104, 105, 120, $124,129,141$ and 151 show this material, but all other locations are to be treated as ACBM. 
8. Brake shoes manufactured for hoists, trolleys and bridge drives that are in place and in the 400 store stock (Building 4732) shall be treated as ACBM until proved otherwise (see Picture/Location numbers 147 and 150).

9. The expansion joint material for the oil-fired heaters in the DHXs are known to be ACBM and shall be handled as such. The asbestos percentage is not known at this time, but will be sampled as required. See drawing number 71-02-40265F151, RaybestosManhattan.

10. Buried cable may be contained within pipe made with asbestos. Upon excavation or repair, be aware of possible ACBM in the 400 Area. 
HNF-SD-FF-DP-008

Revision 6

Appendix A

Page 5 of 26

\begin{tabular}{|c|c|c|c|}
\hline \multicolumn{4}{|c|}{ SUSPECT ACBM LOCATION SAMPLING/FFTF-400 AREA } \\
\hline $\begin{array}{l}\text { Picture/ } \\
\text { Item No. }\end{array}$ & $\begin{array}{l}\text { Building- } \\
\text { Cell/Room or } \\
\text { Location }\end{array}$ & $\begin{array}{l}\text { Object and/or Location in Cell or } \\
\text { Room }\end{array}$ & Comments/Condition \\
\hline 01 & $\begin{array}{l}\text { 4713D, } \\
\text { Outside/South }\end{array}$ & $\begin{array}{l}\text { HVAC duct and filter Southeast side- } \\
\text { inside fence at ground level. }\end{array}$ & $\begin{array}{l}18-24 \% \text { Asbestos HEHF Co. } 16699 \mathrm{M} \\
\text { repaired November } 1992 \text {. }\end{array}$ \\
\hline 02 & $\begin{array}{l}4713 \mathrm{D}, \\
\text { Building/Roof }\end{array}$ & $\begin{array}{l}\text { Edge of duct Southeast side-inside fence } \\
\text { at ground level. }\end{array}$ & $\begin{array}{l}18-24 \% \text { Asbestos HEHF Co. } 16699 \mathrm{M} \\
\text { repaired November } 1992\end{array}$ \\
\hline 03 & $\begin{array}{l}4713 \mathrm{D}, \\
\text { Building/Roof }\end{array}$ & $\begin{array}{l}\text { Looking Northwest from top of ladder } \\
\text { on south side of building. }\end{array}$ & $\begin{array}{l}18-24 \% \text { Asbestos HEHF Co. } 16699 \mathrm{M} \\
\text { repaired November } 1992\end{array}$ \\
\hline 04 & $\begin{array}{l}4713 \mathrm{D}, \\
\text { Building/Roof }\end{array}$ & $\begin{array}{l}\text { Looking due west from top of ladder on } \\
\text { south side of building. }\end{array}$ & $\begin{array}{l}18-24 \% \text { Asbestos HEHF Co. } 16699 \mathrm{M} \\
\text { repaired November } 1992\end{array}$ \\
\hline 05 & 484, Inside & Air separator U-606 550 foot elevation. & $\begin{array}{l}3-8 \% \text { Asbestos HEHF Co. } 16595 / \text { see } \\
\text { FO- } 2902 \mathrm{~A}\end{array}$ \\
\hline 06 & 484, Inside & Air separator U-606 550 foot elevation. & $\begin{array}{l}3-8 \% \text { Asbestos HEHF Co. } 16595 \text { see } \\
\text { FO-2902/A }\end{array}$ \\
\hline 07 & 484, Inside & Air separator U-480 550 foot elevation. & $\begin{array}{l}\text { 3-8\% Asbestos HEHF Co. } 16595 \text { repaired } \\
7 / 94\end{array}$ \\
\hline 08 & 484, Inside & Air separator U-479 550 foot elevation. & $\begin{array}{l}\text { 3-8\% Asbestos HEHF Co. } 16595 \text { repaired } \\
7 / 94\end{array}$ \\
\hline 09 & 484, Inside & Tank T-190 550 foot elevation. & $\begin{array}{l}\text { 3-8\% Asbestos HEHF Co. } 16595 \text { see } \\
\text { FO-2902/A. }\end{array}$ \\
\hline 10 & 484, Inside & Top of Tank T-190 550 foot elevation. & $\begin{array}{l}3-8 \% \text { asbestos HEHF Co } 16595 \text { see } \\
\text { FO- } 2902 / \mathrm{A}\end{array}$ \\
\hline 11 & 484, Inside & Tank $T-193550$ foot elevation. & $\begin{array}{l}3-8 \% \text { asbestos HEHF Co } 16678 \text { see } \\
\text { FO- } 2902 / \mathrm{A}\end{array}$ \\
\hline 12 & 484, Inside & Tank T-193 550 foot elevation. & $\begin{array}{l}\text { 10-20\% asbestos HEHF Co } 16678 \text { see } \\
\text { FO- } 2902 / \mathrm{A}\end{array}$ \\
\hline 13 & 484, Inside & Tank T-97A 550 foot elevation. & $\begin{array}{l}15-20 \% \text { asbestos HEHF Co } 16678 \text { see } \\
\text { FO-2902/A }\end{array}$ \\
\hline 14 & 484, Inside & Tank T-97A 570 foot elevation. & $\begin{array}{l}15-20 \% \text { asbestos HEHF Co } 16678 \text { see } \\
\text { FO-2902/A }\end{array}$ \\
\hline 15 & 484 , Inside & Tank T-97A 570 foot elevation. & $\begin{array}{l}15-20 \% \text { asbestos HEHF Co } 16678 \text { see } \\
\text { FO- } 2902 / \mathrm{A}\end{array}$ \\
\hline 16 & 484, Inside & Tank T-97B 570 foot elevation. & $\begin{array}{l}15-20 \% \text { asbestos HEHF Co } 16678 \text { see } \\
\text { FO- } 2902 / \mathrm{A}\end{array}$ \\
\hline 17 & 484, Inside & Pump P-237 550 foot elevation. & No asbestos present HËHF Co 18793 \\
\hline 18 & 484, Inside & Pump P-236 550 foot elevation. & No asbestos present HEHF Co 18793 \\
\hline
\end{tabular}

ACRONYMS: ACBM - Asbestos-Containing Building Material; HVAC - Heating, Ventilation and Air Conditioning; HEHF - Hanford Environmental Health Foundation; DHX - Dump Heat Exchanger; IVHM - In-vessel Handling Machine; PIC - Person-inCharge; FSF - Fuel Storage Facility. 
HNF-SD-FF-DP-008

Revision 6

Appendix A

Page 6 of 26

\begin{tabular}{|c|c|c|c|}
\hline \multicolumn{4}{|c|}{ SUSPECT ACBM LOCATION SAMPLING/FFTF-400 AREA } \\
\hline $\begin{array}{l}\text { Picture/ } \\
\text { Item No. }\end{array}$ & $\begin{array}{l}\text { Building- } \\
\text { Cell/Room or } \\
\text { Location }\end{array}$ & $\begin{array}{l}\text { Object and/or Location in Cell or } \\
\text { Room }\end{array}$ & Comments/Condition \\
\hline 19 & 484, Inside & Valve 23-V-3013 550 foot elevation. & No asbestos present $\mathrm{HEHF}$ Co 18793 \\
\hline 20 & 484, Inside & $\begin{array}{l}\text { Valve } 23-V-3303 \text { at elbow } 550 \text { foot } \\
\text { elevation }\end{array}$ & No asbestos present HEHF Co 18793 \\
\hline 21 & 484, Inside & $\begin{array}{l}\text { Valve } 23-V-3004 \text { at elbow } 550 \text { foot } \\
\text { elevation }\end{array}$ & No asbestos present HEHF Co 18793 \\
\hline 22 & 484, Inside & Evaporator E-144, 550 foot elevation & No asbestos present HEHF Co 18793 \\
\hline 23 & 484 , Inside & Evaporator E-145, 550 foot elevation & No asbestos present HEHF Co 18793 \\
\hline 24 & $408 \mathrm{~A}$ & $\begin{array}{l}550 \text { foot level lights and sight port } \\
\text { gasket near ladder RL-DHX-E-11 }\end{array}$ & $95-98 \%$ asbestos HEHF Co 18793 \\
\hline 25 & $408 \mathrm{~A}$ & Same item as above & 95-98\% asbestos HEHF Co 18793 \\
\hline 26 & $408 \mathrm{~A}$ & $\begin{array}{l}\text { Insulation block material behind metal } \\
\text { flashing E-9 } 570 \text { foot elevation } \\
\text { northeast corner }\end{array}$ & $1 \%$ asbestos HEHF Co 16580 \\
\hline 27 & $408 \mathrm{~A}$ & $\begin{array}{l}\text { Pipe traps P80 OR P143 three places } \\
530 \text { foot level elevation Blackmastic }\end{array}$ & 20-23\% asbestos HEHF Co 18813 \\
\hline 28 & $408 \mathrm{~A}$ & $\begin{array}{l}\text { Part of red rubber at E- } 6 \text { fabric } \\
\text { expansion fan/isolate "White fibrous } \\
\text { rope" } 530 \text { foot level elevation }\end{array}$ & $40-45 \%$ asbestos HEHF Co 18813 \\
\hline 29 & $408 \mathrm{~A}$ & $\begin{array}{l}\text { Tan fibrous insulation-Part of above at } \\
\text { E-6 }\end{array}$ & $80-85 \%$ asbestos HEHF Co 18813 \\
\hline 30 & $408 \mathrm{~A}$ & $\begin{array}{l}\text { View port light gasket at E-7 East, } 550 \\
\text { foot elevation }\end{array}$ & $40-45 \%$ asbestos HEHF Co 18813 \\
\hline 31 & $408 \mathrm{~A}$ & $\begin{array}{l}\text { Manway gasket at E-7 East, } 530 \text { foot } \\
\text { elevation }\end{array}$ & $24-27 \%$ asbestos HEHF Co 18813 \\
\hline 32 & $408 \mathrm{~A}$ & $\begin{array}{l}\text { Rope gasket from Q-3 vent fan, } 530 \text { foot } \\
\text { elevation }\end{array}$ & $60-65 \%$ asbestos HEHF Co 18813 \\
\hline 33 & $408 \mathrm{~A}$ & $\begin{array}{l}\text { Sample from farside of Q-1 preheater at } \\
\text { circ fan bearing, } 530 \text { foot elevation }\end{array}$ & No asbestos present HEHF Co 18813 \\
\hline 34 & $408 \mathrm{~A}$ & $\begin{array}{l}\text { "White gasket material" sample from } \\
\text { Q-1 vent fan, } 530 \text { foot elevation }\end{array}$ & $30-40 \%$ asbestos HEHF Co 18813 \\
\hline 35 & $408 \mathrm{~A}$ & $\begin{array}{l}\text { Sample from service air piping at } \\
\text { southwest corner } 530 \text { foot elevation } \\
\text { below stairs }\end{array}$ & No asbestos present HEHF Co 18813 \\
\hline 36 & $408 \mathrm{~A}$ & $\begin{array}{l}\text { Black tar near R-807 roof, } 555 \text { foot } \\
\text { elevation }\end{array}$ & 5-7\% present HEHF Co 18804 \\
\hline
\end{tabular}

ACRONYMS: ACBM - Asbestos-Containing Building Material; HVAC - Heating, Ventilation and Air Conditioning; HEHF - Hanford Environmental Health Foundation; DHX - Dump Heat Exchanger; IVHM - In-vessel Handling Machine; PIC - Person-inCharge; FSF - Fuel Storage Facility. 
HNF-SD-FF-DP-008

Revision 6

Appendix A

Page 7 of 26

\section{SUSPECT ACBM LOCATION SAMPLING/FFTF-400 AREA}

\begin{tabular}{|c|c|c|c|}
\hline $\begin{array}{l}\text { Picture/ } \\
\text { Item No. }\end{array}$ & $\begin{array}{l}\text { Building- } \\
\text { Cell/Room or } \\
\text { Location }\end{array}$ & $\begin{array}{l}\text { Object and/or Location in Cell or } \\
\text { Room }\end{array}$ & Comments/Condition \\
\hline 37 & $408 \mathrm{~A}, \mathrm{E}-5$ & $\begin{array}{l}\text { Tan fibrous insulation from light and } \\
\text { sight view ports, } 530 \text { foot elevation near } \\
\text { ladder L-DHX-E15 }\end{array}$ & $95-98 \%$ asbestos HEHF Co 18804 \\
\hline 38 & $408 \mathrm{~A}, \mathrm{E}-5$ & $\begin{array}{l}\text { Tan fibrous insulation from light and } \\
\text { sight view ports, } 530 \text { foot elevation near } \\
\text { ladder L-DHX-E16 }\end{array}$ & $95-98 \%$ asbestos HEHF Co 18804 \\
\hline 39 & $408 \mathrm{~A}, \mathrm{E}-5$ & $\begin{array}{l}\text { Tan fibrous insulation from light and } \\
\text { sight view ports, } 500 \text { foot elevation near } \\
\text { ladder L-DHX-E16 }\end{array}$ & 95-98\% asbestos HEHF Co 18804 \\
\hline 40 & $408 \mathrm{~A}, \mathrm{E}-5$ & $\begin{array}{l}\text { Tan fibrous insulation from manway } \\
530 \text { foot elevation near GPE-377 }\end{array}$ & $95-98 \%$ asbestos HEHF Co 18804 \\
\hline 41 & $408 \mathrm{~A}, \mathrm{E}-4$ & $\begin{array}{l}\text { Tan fibrous insulation from light and } \\
\text { sight view ports, } 530 \text { foot elevation near } \\
\text { ladder L-DHX-E-4 }\end{array}$ & 80-85\% asbestos HEHF Co 18804 \\
\hline 42 & $408 \mathrm{~A}, \mathrm{E}-5$ & $\begin{array}{l}\text { Sprayed on insulation } 570 \text { foot elevation } \\
\text { above }\end{array}$ & No asbestos present HEHF Co 18816 \\
\hline 43 & $408 \mathrm{~A}, \mathrm{E}-5$ & Sprayed on insulation 570 foot & No asbestos present HEHF Co 18816 \\
\hline 44 & $408 \mathrm{~A}, \mathrm{E}-5$ & $\begin{array}{l}\text { Gasket material around light and sight } \\
\text { view port hole, } 550 \text { foot elevation near } \\
\text { ladder L-DHX-E- } 18\end{array}$ & $80-90 \%$ asbestos HEHF Co 18816 \\
\hline 45 & $408 \mathrm{~A}, \mathrm{E}-5$ & $\begin{array}{l}\text { White gasket material around light and } \\
\text { sight view ports, } 550 \text { foot elevation near } \\
\text { ladder L-DHX-23 }\end{array}$ & $95-98 \%$ asbestos HEHF Co 18816 \\
\hline 46 & $408 \mathrm{~A}, \mathrm{E}-6$ & Ceramic fiber, 550 foot elevation & No asbestos present HEHF Co 18816 \\
\hline 47 & $\begin{array}{l}\text { Southeast } \\
\text { Outside } 491 E \text {, } \\
\text { U-781-A }\end{array}$ & $\begin{array}{l}\text { Black tar paper and white powder } \\
\text { southeast corner of auxiliary east } \\
\text { containment margins equipment }\end{array}$ & $\begin{array}{l}\text { 4-10\% asbestos HEHF Co } 18816 \text { over all } \\
\text { composition }\end{array}$ \\
\hline 48 & $\begin{array}{l}\text { Southeast } \\
\text { Outside of } 491 \\
\text { U-781B }\end{array}$ & $\begin{array}{l}\text { Black fibrous tar paper southeast corner } \\
\text { of auxiliary east containment margins } \\
\text { equipment }\end{array}$ & 16-24\% asbestos HEHF Co 18816 \\
\hline 49 & $\begin{array}{l}\text { Southeast } \\
\text { Outside of } \\
491 E, U-781-C\end{array}$ & $\begin{array}{l}\text { Black fibrous tar paper and tan fibrous } \\
\text { clumps southeast corner of auxiliary } \\
\text { east containment margins equipment }\end{array}$ & $\begin{array}{l}16-24 \% \text { asbestos HEHF Co } 18816 \text { over all } \\
\text { composition }\end{array}$ \\
\hline 50 & $\begin{array}{l}4713-D, \text { all } \\
\text { locations }\end{array}$ & $\begin{array}{l}\text { Green floor tiles manipulator shop, east } \\
\text { end }\end{array}$ & $\begin{array}{l}2-4 \% \text { chrysotile asbestos HEHF Co } 18926 \\
\text { redo }\end{array}$ \\
\hline
\end{tabular}

ACRONYMS: $\quad$ ACBM - Asbestos-Containing Building Material; HVAC - Heating, Ventilation and Air Conditioning; HEHF - Hanford Environmental Health Foundation; DHX - Dump Heat Exchanger; IVHM - In-vessel Handling Machine; PIC - Person-inCharge; FSF - Fuel Storage Facility. 
HNF-SD-FF-DP-008

Revision 6

Appendix A

Page 8 of 26

\begin{tabular}{|c|c|c|c|}
\hline \multicolumn{4}{|c|}{ SUSPECT ACBM LOCATION SAMPLING/FFTF-400 AREA } \\
\hline $\begin{array}{l}\text { Picture/ } \\
\text { Item No. }\end{array}$ & $\begin{array}{l}\text { Building- } \\
\text { Cell/Room or } \\
\text { Location }\end{array}$ & $\begin{array}{l}\text { Object and/or Location in Cell or } \\
\text { Room }\end{array}$ & Comments/Condition \\
\hline 51 & 409B, E-76 & $\begin{array}{l}\text { Red expansion point material-four } \\
\text { places southwest corner }\end{array}$ & $35-40 \%$ asbestos HEHF Co 18834 \\
\hline 52 & $409 \mathrm{~B}, \mathrm{E}-76$ & $\begin{array}{l}\text { Cloth material southwest corner at pipe } \\
\text { penetration in slab }\end{array}$ & No asbestos present HEHF Co 18834 \\
\hline 53 & $409 \mathrm{~B}, \mathrm{E}-76$ & Black gasket material southwest corner & $40-45 \%$ asbestos HEHF Co 18834 \\
\hline 54 & $409 \mathrm{~B}, \mathrm{E}-76$ & $\begin{array}{l}\text { Black gasket material around light and } \\
\text { sight port southwest corner }\end{array}$ & $40-45 \%$ asbestos HEHF Co 18834 \\
\hline 55 & 409B, E-76 & $\begin{array}{l}\text { Red rubber gasket shroud southeast } \\
\text { corner }\end{array}$ & 20-30\% asbestos HEHF Co 18834 \\
\hline 56 & 409B, E-76 & $\begin{array}{l}\text { Gasket material around light and sight } \\
\text { port windows }\end{array}$ & 20-30\% asbestos HEHF Co 18834 \\
\hline 57 & 409B, E-76 & $\begin{array}{l}\text { CERA blankèt behind stainless flashing } \\
\text { at fan damper }\end{array}$ & No asbestos present HEHF Co 18834 \\
\hline 58 & 408B, E-76 & $\begin{array}{l}\text { Red canvas material at the } 570 \text { foot } \\
\text { level CLS dump heat exchangers } \\
\text { preheater exhaust }\end{array}$ & $\begin{array}{l}14-21 \% \text { asbestos over all composition HEHF } \\
\text { Co } 18834\end{array}$ \\
\hline 59 & 409B, E-76 & $\begin{array}{l}\text { Black gasket material at the } 570 \text { foot } \\
\text { level around light and sight port } \\
\text { windows }\end{array}$ & $40-60 \%$ asbestos HEHF Co 18834 \\
\hline 60 & 409B, E-76 & $\begin{array}{l}\text { Gasket material at the } 570 \text { foot level } \\
\text { around windows }\end{array}$ & $50-65 \%$ asbestos HEHF Co 18834 \\
\hline 61 & 409A, Roof & $\begin{array}{l}\text { Roof material near R-1 outside on roof } \\
\text { on northeast side }\end{array}$ & $\begin{array}{l}15-20 \% \text { asbestos HEHF Co } 18834 \text {, repaired } \\
\text { October } 1993\end{array}$ \\
\hline 62 & 409A, Roof & $\begin{array}{l}\text { Gasket material near R-1 outside on } \\
\text { roof on north side, east of low roof }\end{array}$ & No asbestos present HEHF Co 18834 \\
\hline 63 & 409A, Roof & $\begin{array}{l}\text { Insulkote mud on fuel oil piping elbow } \\
\text { near R-3 outside on roof northeast side }\end{array}$ & 6-12\% asbestos HEHF Co 18834 \\
\hline 64 & 491-E, Roof & $\begin{array}{l}\text { Outer layer of duct covering southeast } \\
\text { corner near E- } 615\end{array}$ & $\begin{array}{l}\text { No asbestos present HEHF Co } 18837 \\
\text { repaired October } 1993\end{array}$ \\
\hline 65 & 491-E, Roof & $\begin{array}{l}\text { Inner layer of duct covering southeast } \\
\text { comer near E-615 }\end{array}$ & $\begin{array}{l}15-20 \% \text { present HEHF Co } 18837 \text { repaired } \\
\text { October } 1993\end{array}$ \\
\hline 66 & 491-E, Roof & Roof walk pads at all locations & $\begin{array}{l}5-8 \% \text { asbestos HEHF Co } 18837 \text { repaired } \\
\text { October } 1993\end{array}$ \\
\hline 67 & 49l-E, Roof & Mud on elbows southwest corner & $\begin{array}{l}\text { No asbestos present HEHF Co } 18862 \\
\text { repaired October } 1993\end{array}$ \\
\hline
\end{tabular}

ACRONYMS: ACBM - Asbestos-Containing Building Material; HVAC - Heating, Ventilation and Air Conditioning; HEHF - Hanford Environmental Health Foundation; DHX - Dump Heat Exchanger; IVHM - In-vessel Handling Machine; PIC - Person-inCharge; FSF - Fuel Storage Facility. 
HNF-SD-FF-DP-008

Revision 6

Appendix A

Page 9 of 26

\begin{tabular}{|c|c|c|c|}
\hline \multicolumn{4}{|c|}{ SUSPECT ACBM LOCATION SAMPLING/FFTF-400 AREA } \\
\hline $\begin{array}{l}\text { Picture/ } \\
\text { Item No. }\end{array}$ & $\begin{array}{l}\text { Building- } \\
\text { Cell/Room or } \\
\text { Location }\end{array}$ & $\begin{array}{l}\text { Object and/or Location in Cell or } \\
\text { Room }\end{array}$ & Comments/Condition \\
\hline 68 & 491-E, Roof & Mud on valves southwest corner & No asbestos present HEHF Co 18862 \\
\hline 69 & $\begin{array}{l}4621-W, \text { Roof } \\
\text { lower }\end{array}$ & $\begin{array}{l}\text { West roof above E- } 68 \text { air conditioner } \\
\text { black Insulkote on duct }\end{array}$ & $\begin{array}{l}5-8 \% \text { asbestos HEHF Co } 18862 \text { repaired } \\
\text { October } 1993\end{array}$ \\
\hline 70 & $\begin{array}{l}4621-W, \text { Roof } \\
\text { lower }\end{array}$ & $\begin{array}{l}\text { West roof - mud on elbow at E- } 68 \text { air } \\
\text { conditioner }\end{array}$ & No asbestos present HEHF Co 18862 \\
\hline 71 & $\begin{array}{l}4621-W, \text { Roof } \\
\text { lower }\end{array}$ & Black Insulkote at 25-BD-0701 & $\begin{array}{l}\text { 3-5\% asbestos HEHF Co } 18862 \text { repaired } \\
\text { October } 1993\end{array}$ \\
\hline 72 & $\begin{array}{l}4621-W, \text { Roof } \\
\text { lower }\end{array}$ & Black walkway at E- 67 air conditioner & $\begin{array}{l}\text { No asbestos present HEHF Co } 18862 \\
\text { repaired October } 1993\end{array}$ \\
\hline 73 & $\begin{array}{l}491-\$, \text { Roof } \\
\text { lower }\end{array}$ & $\begin{array}{l}\text { Mud elbow at deionized water pipe near } \\
\text { elbow asbestos found at other elbow. } \\
\text { All insulation removed February } 1995 \\
\text { per work package 4F-91-1984/W }\end{array}$ & No asbestos present HEHF Co 18862 \\
\hline 74 & $\begin{array}{l}4621-W, \text { Roof } \\
\text { lower }\end{array}$ & Expansion joint at E-68 air conditioner & 20-25\% asbestos HEHF Co 18862 \\
\hline 75 & 405, Cell 578 & $\begin{array}{l}\text { Mud from elbow at E-202 cooler see } \\
\text { Pic/Item } 66\end{array}$ & No asbestos present HEHF Co 18868 \\
\hline 76 & 405 , Cell 578 & Mud from elbow at E-216 & No asbestos present HEHF Co 18868 \\
\hline 77 & 405, Cell 578 & Mud on elbow by rack 168 & No asbestos present HEHF Co I 8868 \\
\hline 78 & 405, Cell 578 & Mud on flange by rack 164 & No asbestos present HEHF Co 18868 \\
\hline 79 & 403 , Room 900 & Ceiling tiles in control room & No asbestos present HEHF Co 18868 \\
\hline 80 & 403, Room 900 & $\begin{array}{l}\text { Fireproofing on steel above control } \\
\text { room ceiling }\end{array}$ & No asbestos present HEHF Co 18868 \\
\hline 81 & 403, Cell 564 & $\begin{array}{l}\text { Fire retardant on top of C-840A preheat } \\
\text { power control panel }\end{array}$ & No asbestos present HEHF Co 18874 \\
\hline 82 & 405, Cell 561 & Mud elbow from near E-201R cooler & No asbestos present HEHF Co 18874 \\
\hline 83 & 405 , Cell 577 & Mud elbow E- 215 cooler & No asbestos present HEHF Co 18874 \\
\hline 84 & 405, Cell 572 & Mud blank from near SV-87950 & No asbestos present HEHF Co 18874 \\
\hline 85 & $\begin{array}{l}\text { 491-S, } \\
\text { Room } 484\end{array}$ & $\begin{array}{l}\text { Dip Lag and mud at elbow from } \\
\text { TV- } 86527\end{array}$ & No asbestos present HEHF Co 18874 \\
\hline 86 & $\begin{array}{l}491-\mathrm{S} \\
\text { Room } 484\end{array}$ & Dip-lab and mud at elbow 23-V-4385 & No asbestos present HEHF Co 18874 \\
\hline 87 & $\begin{array}{l}491-\mathrm{S} \\
\text { Room } 484\end{array}$ & $\begin{array}{l}\text { Fire retardant spray on C-986 control } \\
\text { cabinet }\end{array}$ & No asbestos present HEHF Co 18874 \\
\hline
\end{tabular}

ACRONYMS: ACBM - Asbestos-Containing Building Material; HVAC - Heating, Ventilation and Air Conditioning; HEHF - Hanford Environmental Health Foundation; DHX - Dump Heat Exchanger; IVHM - In-vessel Handling Machine; PIC - Person-inCharge; FSF - Fuel Storage Facility. 
HNF-SD-FF-DP-008

Revision 6

Appendix A

Page 10 of 26

\begin{tabular}{|c|c|c|c|}
\hline \multicolumn{4}{|c|}{ SUSPECT ACBM LOCATION SAMPLING/FFTF-400 AREA } \\
\hline $\begin{array}{l}\text { Picturef } \\
\text { Item No. }\end{array}$ & $\begin{array}{l}\text { Building- } \\
\text { Cell/Room or } \\
\text { Location }\end{array}$ & $\begin{array}{l}\text { Object and/or Location in Cell or } \\
\text { Room }\end{array}$ & Comments/Condition \\
\hline 88 & $\begin{array}{l}\text { 4621-E, } \\
\text { Room } 309\end{array}$ & Mud on elbow near valve $23-\mathrm{V}-1209$ & No asbestos present HEHF Co 18920 \\
\hline 89 & $\begin{array}{l}\text { 4621-E, } \\
\text { Room } 309\end{array}$ & $\begin{array}{l}\text { Mud on elbow near diesel generator tag } \\
\text { E-340 }\end{array}$ & No asbestos present HEHF Co 18920 \\
\hline 90 & $\begin{array}{l}4703, \\
\text { Room } 121\end{array}$ & Ceiling tiles at FFTF main entrance & No asbestos present HEHF Co 18920 \\
\hline 91 & $\begin{array}{l}4703, \\
\text { Room } 106\end{array}$ & Ceiling tiles above valve $26-\mathrm{V}-503$ & No asbestos present HEHF Co 18920 \\
\hline 92 & $\begin{array}{l}4703, \\
\text { Room } 108\end{array}$ & Elbow/straight piece near PI-70031 & No asbestos present HEHF Co 18920 \\
\hline 93 & $\begin{array}{l}4703, \\
\text { Room } 108 \\
\end{array}$ & $\begin{array}{l}\text { Flammastic material on cable tray near } \\
\text { hanger } 108-1-02\end{array}$ & $1-2 \%$ asbestos HEHF Co 18920 \\
\hline 94 & $\begin{array}{l}4703, \\
\text { Room } 101\end{array}$ & Mud on valve $23-V-4356$ & No asbestos present $\mathrm{HEHF}$ Co 18920 \\
\hline 95 & $\begin{array}{l}4621-\mathrm{E}, \\
\text { Room } 331\end{array}$ & Mud on elbow near valve $23-V-2746$ & No asbestos present HEHF Co 18926 \\
\hline 96 & $\begin{array}{l}4621-\mathrm{E} \\
\text { Room } 331 \\
\end{array}$ & Mud on elbow near TV-85456 & No asbestos present HEHF Co 18926 \\
\hline 97 & $\begin{array}{l}4621-\mathrm{E} \\
\text { Room } 331 \\
\end{array}$ & $\begin{array}{l}\text { Motor control center cabinet B-20 } \\
\text { sprayed on flammastic }\end{array}$ & No asbestos present HEHF Co $18926 / 19070$ \\
\hline 98 & $\begin{array}{l}4621-\mathrm{E} \\
\text { Room } 332\end{array}$ & Mud on elbow near tag E-521 & No asbestos present HEHF Co 18926 \\
\hline 99 & $\begin{array}{l}\text { 4621-E, } \\
\text { Room } 332\end{array}$ & Mud on flange on E-519 & No asbestos present HEHF Co 18926 \\
\hline 100 & $408 \mathrm{~A}$ & $\begin{array}{l}\text { EL530 mud from DHX-Q2 heater by } \\
\text { R-831 induced draft fan }\end{array}$ & No asbestos present HEHF Co 18926 \\
\hline 101 & $408 \mathrm{~A}$ & $\begin{array}{l}\text { EL530 mud from DHX-Q2 heater by } \\
\text { R-831 induced draft fan }\end{array}$ & No asbestos present HEHF Co 18926 \\
\hline 102 & $408 \mathrm{~A}$ & $\begin{array}{l}\text { EL560 DHX-east roof outside tag } \\
23-\mathrm{V}-5135 \text { black Insulkote }\end{array}$ & 5-10\% Chrysotile asbestos HEHF Co 18926 \\
\hline 103 & 4717,258 & Elbow tank T-13A & No asbestos present HEHF Co 18930 \\
\hline 104 & 4717,258 & Black insulation from top T-13A & $3-8 \%$ asbestos HEHF Co 18930 \\
\hline 105 & 4717,258 & Black insulation top of tank T-13B & 3-8\% Chrysotile asbestos HEHF Co 18930 \\
\hline
\end{tabular}

ACRONYMS: ACBM - Asbestos-Containing Building Material; HVAC - Heating, Ventilation and Air Conditioning; HEHF - Hanford Environmental Health Foundation; DHX - Dump Heat Exchanger; IVHM - Ini-vessel Handling Machine; PIC - Person-inCharge; FSF - Fuel Storage Facility. 


\begin{tabular}{|c|c|c|c|}
\hline \multicolumn{4}{|c|}{ SUSPECT ACBM LOCATION SAMPLING/FFTF-400 AREA } \\
\hline $\begin{array}{l}\text { Picture/ } \\
\text { Item No. }\end{array}$ & $\begin{array}{l}\text { Building- } \\
\text { Cell/Room or } \\
\text { Location }\end{array}$ & $\begin{array}{l}\text { Object and/or Location in Cell or } \\
\text { Room }\end{array}$ & Comments/Condition \\
\hline 106 & 4717,258 & $\begin{array}{l}\text { Mud elbow on instrument air line tag } \\
23-V-4169\end{array}$ & No asbestos present HEHF Co 18930 \\
\hline 107 & 4717,258 & $\begin{array}{l}\text { Insulation from tower tank } \mathrm{T}-194 \\
\text { Tower } 1\end{array}$ & No asbestos present HEHF Co 18930 \\
\hline 108 & 4717,258 & Insulation from top of the $T-25$ tower & No asbestos present HEHF Co 18930 \\
\hline 109 & 4717,258 & $\begin{array}{l}\text { Insulation from tower } \mathrm{T} \text { - } 194 \text { Tower } 2 \\
\text { drain hole at knee level }\end{array}$ & $3-5 \%$ asbestos HEHF Co 18930 \\
\hline 110 & $\begin{array}{l}4621-W \\
\text { Room } 366\end{array}$ & $\begin{array}{l}\text { Insulation from lube oil cooler tag } \\
\text { E-320 }\end{array}$ & No asbestos present HEHF Co 18948 \\
\hline 111 & $\begin{array}{l}4621-W . \\
\text { Room } 366\end{array}$ & $\begin{array}{l}\text { Insulation from elbow tag } \\
\text { VDPSH66093A }\end{array}$ & No asbestos present HEHF Co 18948 \\
\hline 112 & $\begin{array}{l}4621-W \\
\text { Room } 366\end{array}$ & Insulation from trap tag $23-\mathrm{V}-1820$ & No asbestos present HEHF Co 18948 \\
\hline 113 & $\begin{array}{l}4621-W \\
\text { Room } 366\end{array}$ & Insulation from trap tag 1592 & No asbestos present HEHF Co 18948 \\
\hline 114 & $\begin{array}{l}4621-W \\
\text { Room } 365\end{array}$ & Insulation from flange tag E-651 & No asbestos present HEHF Co 18941 \\
\hline 115 & $\begin{array}{l}4621-W \\
\text { Room } 365\end{array}$ & Insulation from elbow tag E-652 & No asbestos present HEHF Co 18948 \\
\hline 116 & $\begin{array}{l}4621-W \\
\text { Room } 365\end{array}$ & Insulation from plus tag VFE75689B & No asbestos present HEHF Co 18948 \\
\hline 117 & $\begin{array}{l}4621-W \\
\text { Room } 354\end{array}$ & $\begin{array}{l}\text { Insulation from elbow on chilled water } \\
\text { line at tree }\end{array}$ & No asbestos present HEHF Co 18955 \\
\hline 118 & $\begin{array}{l}\text { 4621-W, } \\
\text { Room } 356\end{array}$ & $\begin{array}{l}\text { Insulation from elbow on chilled water } \\
\text { line tag } 356-1-04\end{array}$ & No asbestos present HEHF Co 18955 \\
\hline 119 & $\begin{array}{l}4621-W, \\
\text { Room } 361\end{array}$ & Insulation from valve tag $23-V-4373$ & No asbestos present HEHF Co 18955 \\
\hline 120 & 436 , Outside & $\begin{array}{l}\text { Black insulation on duct East side of } \\
\text { building }\end{array}$ & 10-20\% asbestos HEHF Co 18958 \\
\hline 121 & 436 , Outside & $\begin{array}{l}\text { Insulation cloth material from duct work } \\
\text { East side of building }\end{array}$ & No asbestos present HEHF Co 18958 \\
\hline 122 & 491-S, Cell 497 & Insulation from EM pump blower R188 & No asbestos present HEHF Co 18958 \\
\hline 123 & $408 \mathrm{~B}$ & $\begin{array}{l}\text { Q-6 induced draft fan asbestos gasket } \\
\text { material }\end{array}$ & $\begin{array}{l}10-20 \% \text { Chrysotile asbestos HEHF } \\
\text { Co } 18960\end{array}$ \\
\hline
\end{tabular}

ACRONYMS: ACBM - Asbestos-Containing Building Material; HVAC - Heating, Ventilation and Air Conditioning; HEHF - Hanford Environmental Health Foundation; DHX - Dump Heat Exchanger; IVHM - In-vessel Handling Machine; PIC - Person-inCharge; FSF - Fuel Storage Facility. 
HNF-SD-FF-DP-008

Revision 6

Appendix A

Page 12 of 26

\begin{tabular}{|c|c|c|c|}
\hline \multicolumn{4}{|c|}{ SUSPECT ACBM LOCATION SAMPLING/FFTF-400 AREA } \\
\hline $\begin{array}{l}\text { Picture/ } \\
\text { Item No. }\end{array}$ & $\begin{array}{l}\text { Building- } \\
\text { Cell/Room or } \\
\text { Location }\end{array}$ & $\begin{array}{l}\text { Object and/or Location in Cell or } \\
\text { Room }\end{array}$ & Comments/Condition \\
\hline 124 & $483 \cdot$ & Insulation from elbow below box GAB3 & No asbestos present HEHF Co 18982 \\
\hline 125 & 481 & $\begin{array}{l}\text { Gasket material on fire prot. Water line } \\
\text { FE- } 68014\end{array}$ & 60-80\% Chrysotile HEHF Co 18982 \\
\hline 126 & 4717, Cell 244 & Mud from valve by tank U-604 & No asbestos present HEHF Co 18982 \\
\hline 127 & 403, Cell 902 & Mud on flange by tag 0411-05BB & No asbestos present HEHF Co 18994 \\
\hline 128 & $\begin{array}{l}491-W, \text { Cell } \\
435\end{array}$ & $\begin{array}{l}\text { Mud by hanger on secondary sodium } \\
\text { line by tag Q } 46950-B\end{array}$ & No asbestos present HEHF Co 18994 \\
\hline 129 & $\begin{array}{l}4621-W \\
\text { Room } 366\end{array}$ & $\begin{array}{l}\text { Black material north west corner by wall } \\
\text { cooling water line heat trace throughout } \\
\text { floor }\end{array}$ & 5-8\% Chrysotile HEHF Co 19007 \\
\hline 130 & 405,501 & Floor tile IVHM control room & No asbestos present HEHF Co 19016 \\
\hline 131 & 405,501 & Ceiling panel IVHM control room & No asbestos present HEHF Co 19016 \\
\hline 132 & 405,501 & Ceiling panel IVHM control room & No asbestos present HEHF Co 19016 \\
\hline 133 & 405,500 & $\begin{array}{l}\text { Valve on chill water line by air cooler } \\
\text { E- } 26\end{array}$ & No asbestos present HEHF Co 19016 \\
\hline 134 & 405,500 & $\begin{array}{l}\text { Valve on chill water line tag } 23-V-1456 \\
\text { by air cooler E- } 26\end{array}$ & No asbestos present HEHF Co 19016 \\
\hline 135 & $\begin{array}{l}437, \\
\text { Stairwell \#2 }\end{array}$ & Floor tile in stairwell $\# 2$ by door 121 & No asbestos present HEHF Co 19020 \\
\hline 136 & 437, Cell \#3 & $\begin{array}{l}\text { Large diameter cleaning vessel at valve } \\
\text { asbestos present behind metal skin }\end{array}$ & No asbestos present HEHF Co 19020 \\
\hline 137 & 437, Cell $\# 3$ & $\begin{array}{l}\text { Large diameter cleaning vessel asbestos } \\
\text { present behind metal skin }\end{array}$ & No asbestos present HEHF Co 19020 \\
\hline 138 & $408 \mathrm{~A}, \mathrm{E}-5$ & $\begin{array}{l}570 \text { foot elevation fabric gasket (metal) } \\
\text { to (metal) southeast corner E-5 damper } \\
\text { frame }\end{array}$ & No asbestos present HEHF Co 19021 \\
\hline 139 & $408 \mathrm{~A}, \mathrm{E}-5$ & $\begin{array}{l}565 \text { foot elevation manway gasket into } \\
\text { E-5 white fiberous gasket }\end{array}$ & $\begin{array}{l}90-95 \% \text { Chrysotile asbestos HEHF } \\
\text { Co } 19021\end{array}$ \\
\hline 140 & 481 & $\begin{array}{l}\text { Fire line gasket at east end of building } \\
\text { outside }\end{array}$ & 80-90\% Chrysotile HEHF Co 19053 \\
\hline 141 & $4621-W, 365$ & $\begin{array}{l}\text { Firewater line into room } 365 \text { by heat } \\
\text { trace box tag S- } 68\end{array}$ & $\begin{array}{l}10-15 \% \text { Chrysotile HEHF Co } 19053 \text {, } \\
\text { Recovered November } 1997\end{array}$ \\
\hline 142 & $4621-W, 365$ & $\begin{array}{l}\text { Flammastic on cable trays BNO1N5 by } \\
\text { B90 }\end{array}$ & 3-5\% Chrysotile HEHF Co $16627 /$ Co 19053 \\
\hline
\end{tabular}

ACRONYMS: ACBM - Asbestos-Containing Building Material; HVAC - Heating, Ventilation and Air Conditioning; HEHF - Hanford Environmental Health Foundation; DHX - Dump Heat Exchanger; IVHM - In-vessel Handling Machine; PIC - Person-inCharge; FSF - Fuel Storage Facility. 
HNF-SD-FF-DP-008

Revision 6

Appendix A

Page 13 of 26

\begin{tabular}{|c|c|c|c|}
\hline \multicolumn{4}{|c|}{ SUSPECT ACBM LOCATION SAMPLING/FFTF-400 AREA } \\
\hline $\begin{array}{l}\text { Picture/ } \\
\text { Item No. }\end{array}$ & $\begin{array}{l}\text { Building- } \\
\text { Cell/Room or } \\
\text { Location }\end{array}$ & $\begin{array}{l}\text { Object and/or Location in Cell or } \\
\text { Room }\end{array}$ & Comments/Condition \\
\hline 143 & $4621-W, 365$ & Flammastic on B90 electrical unit (top) & 3-5\% Chrysotile HEHF Co $16627 /$ Co 19053 \\
\hline 144 & 4713-B & $\begin{array}{l}\text { Door at loading dock floor tile and } \\
\text { black mastic }\end{array}$ & $\begin{array}{l}\text { Black mastic } 15-18 \% \text { Chrysotile HEHF } \\
\text { Co } 19053\end{array}$ \\
\hline 145 & $4713-\mathrm{B}, 143$ & Valve repair shop floor tile & No asbestos present HEHF Co 19053 \\
\hline 146 & 491-E, Cell 419 & White ceramic fiber by tag 27-V-0001 & No asbestos present HEHF Co 19070 \\
\hline 147 & Any & Crane brake shoe "old" (sent to scrap) & 20-50\% Chrysotile HEHF Co 19070 \\
\hline 148 & Any & $\begin{array}{l}\text { Anaconda/Hayeg power and control } \\
\text { cable "white" }\end{array}$ & $\begin{array}{l}\text { Inner white wrap 100\% Chrysotile HEHF } \\
\text { Co } 19070\end{array}$ \\
\hline 149 & Any & "Yellow" power cable & $\begin{array}{l}\text { Yellow covering } 95-98 \% \text { Chrysotile HEHF } \\
\text { Co } 19070\end{array}$ \\
\hline 150 & Any & $\begin{array}{l}\text { "New" crane brake shoe (located in } \\
\text { stores) }\end{array}$ & No asbestos present HEHF Co 19070 \\
\hline 151 & 483 & $\begin{array}{l}\text { Elbows on cooling towers "black } \\
\text { fiberous tar" }\end{array}$ & No asbestos present HEHF Co 19070 \\
\hline 152 & $\begin{array}{l}491-S, \text { Cell } 489 \\
530 \text { level }\end{array}$ & $\begin{array}{l}\text { White gasket material on inert gad ducts } \\
\text { (previous sample taken) }\end{array}$ & $\begin{array}{l}\text { Room closed no entry } 55-70 \% \text { Chrysotile } \\
\text { HEHF Co } 16853\end{array}$ \\
\hline 153 & $491-\mathrm{E}, 438$ & White floor tile & 2-4\% Chrysotile HEHF Co 19070 \\
\hline 154 & $\begin{array}{l}\text { 4713-A, } \\
\text { Hallway }\end{array}$ & White floor tile & 1-2\% Chrysotile HEHF Co 19070 \\
\hline 155 & 4710, Roof & Black tar with silver paint & No asbestos present HEHF Co 19072 \\
\hline 156 & $491-E, 418$ & Liquid rheostat housing inside cabinet & Asbestos in housing amount unknown \\
\hline 156 & $491-E, 429$ & Liquid rheostat housing inside cabinet & Asbestos in housing amount unknown \\
\hline 156 & $491-\mathrm{E}, 447$ & Liquid rheostat housing inside cabinet & Asbestos in housing amount unknown \\
\hline 157 & $\begin{array}{l}483, \text { East off } \\
\text { paid }\end{array}$ & $\begin{array}{l}\text { Valve box cover removed ACM } \\
\text { October } 1994\end{array}$ & 40-50\% Chrysotile HEHF Co 18006 \\
\hline 158 & 4703,136 & Tile and adhesive at drain floor hole & 2-4\% Chrysotile HEHF Co 19086 \\
\hline 159 & 4703,136 & Light gray floor tile & No asbestos present HEHF Co 19086 \\
\hline 160 & $\begin{array}{l}4713-\mathrm{B}, \text { North } \\
\text { hallway }\end{array}$ & Floor tile in electrical shop & No asbestos present HEHF Co 19086 \\
\hline 161 & $4621-\mathrm{E}, 323$ & Green floor tile & 2-4\% Chrysotile HEHF Co 19086 \\
\hline 162 & $4621-\mathrm{E}, 319$ & Black wall guard at tornado door 130 & No asbestos present HEHF Co 19086 \\
\hline 163 & $491-\mathrm{E}, 438$ & White/tan floor tile & 2-5\% Chrysotile HEHF Co 19086 \\
\hline
\end{tabular}

ACRONYMS: ACBM - Asbestos-Containing Building Material; HVAC - Heating, Ventilation and Air Conditioning; HEHF - Hanford Environmental Health Foundation; DHX - Dump Heat Exchanger; IVHM - In-vessel Handling Machine; PIC - Person-inCharge; FSF - Fuel Storage Facility. 
HNF-SD-FF-DP-008

Revision 6

Appendix A

Page 14 of 26

\begin{tabular}{|c|c|c|c|}
\hline \multicolumn{4}{|c|}{ SUSPECT ACBM LOCATION SAMPLING/FFTF-400 AREA } \\
\hline $\begin{array}{l}\text { Picture/ } \\
\text { Item No. }\end{array}$ & $\begin{array}{l}\text { Building- } \\
\text { Cell/Room or } \\
\text { Location }\end{array}$ & $\begin{array}{l}\text { Object and/or Location in Cell or } \\
\text { Room }\end{array}$ & Comments/Condition \\
\hline 164 & $408 \mathrm{~A}, \mathrm{Q}-2$ & $\begin{array}{l}\text { Expansion joint on Q-2 preheater at } \\
545 \text { foot level no sample taken-same } \\
\text { material as Pic/Item No. } 037 \text { or } 040\end{array}$ & $95-98 \%$ Chrysotile HEHF Co 18813 \\
\hline $165 \mathrm{~A}$ & $408-B, Q-6$ & Outer door gasket on Q-6 preheater & No asbestos present HEHF Co 19021 \\
\hline $165 \mathrm{~B}$ & 408-B, Q-6 & Inner door gasket on Q-6 preheater & No asbestos present HEHF Co 19021 \\
\hline 166 & $4842+B$ & $\begin{array}{l}\text { Sheets on inside of motor control center } \\
\text { doors B130 and B131 }\end{array}$ & 95-98\% Chrysotile HEHF Co 17299 \\
\hline 167 & 4703,136 & $\begin{array}{l}\text { White/tan floor tile repaired } \\
\text { September } 1994 \text { replaced } 16 \text { tiles }\end{array}$ & $2-5 \%$ Chrysotile same as 163 \\
\hline 168 & $4621 \mathrm{E}, 323$ & $\begin{array}{l}\text { White/tan floor tile repaired } \\
\text { September } 1994 \text { encapsulated/overlay }\end{array}$ & $2-5 \%$ Chrysotile same as 163 \\
\hline 169 & 4717 & Tower (recovered) & \\
\hline 170 & $4621 \mathrm{E}, 332$ & $\begin{array}{l}\text { Adhesive and gasket at HEPA filter } \\
\text { door }\end{array}$ & $\begin{array}{l}\text { Approximately } 1 \% \text { Chrysotile HEHF } \\
\text { Co } 21342\end{array}$ \\
\hline 171 & 4717 & Solid waste cask (old) & 25-35\% Chrysotile W95100L093 \\
\hline 172 & 403, Cell 912 & Pipe and elbow, FSF, NAK drain & No asbestos present \\
\hline 173 & 403, Cell 912 & Housing, heat exchanger, NAK drain & No asbestos present \\
\hline 174 & 405 & CLEM brake shoes & Typical brake composite \\
\hline 175 & 4703,136 & Before and after-control room floor & See picture no. 158 \\
\hline 176 & 4703,104 & Chilled water line $1-1 / 2$ " elbow & No asbestos present, W961002468 \\
\hline 177 & 4703,254 & Chilled water line 4" elbow & No asbestos present, W961002469 \\
\hline 178 & 4717,258 & $\begin{array}{l}\text { R189 Compressor lst stage upper } \\
\text { gasket-to be changed }\end{array}$ & Assumed asbestos gasket \\
\hline 179 & $491 \mathrm{~W}, 457$ & Dried roof tar droppings. & No asbestos present \\
\hline 180 & $408 \mathrm{~B}, \mathrm{E}-10$ & Reused old asbestos gasket & Reworked January 1998 \\
\hline 181 & $408 \mathrm{~B}, \mathrm{E}-8$ & New (non-asbestos) gasket & Replaced January 998 \\
\hline 182 & $\begin{array}{l}4713 \mathrm{~B}, \text { Cage } \\
\text { Lockup }\end{array}$ & $\begin{array}{l}\text { Resistive load bank cards total five } \\
\text { units-three will be changed out and two } \\
\text { units are tagged asbestos containing. }\end{array}$ & See electrical shop supervisor. \\
\hline 183 & Many locations & Sump Tank Covers Gasket & Removed by work package $4 \mathrm{~F}-98-1179 / \mathrm{W}$. \\
\hline 184 & Many locations & Cell to Valve Gaskets & $\begin{array}{l}\text { Encapsulated by work package } \\
\text { 4F-98-1290/W. }\end{array}$ \\
\hline
\end{tabular}

ACRONYMS: ACBM - Asbestos-Containing Building Material; HVAC - Heating, Ventilation and Air Conditioning; HEHF - Hanford Environmental Health Foundation; DHX - Dump Heat Exchanger; IVHM - In-vessel Handling Machine; PIC - Person-inCharge; FSF - Fuel Storage Facility. 
HNF-SD-FF-DP-008

Revision 6

Appendix A

Page 15 of 26

\begin{tabular}{|l|l|l|l|}
\hline \multicolumn{3}{|c|}{ SUSPECT ACBM LOCATION SAMPLING/FFTF-400 AREA } \\
\hline $\begin{array}{l}\text { Picture/ } \\
\text { Item No. }\end{array}$ & $\begin{array}{l}\text { Building- } \\
\text { Cell/Room or } \\
\text { Location }\end{array}$ & $\begin{array}{l}\text { Object and/or Location in Cell or } \\
\text { Room }\end{array}$ & Comments/Condition \\
\hline 185 & $4717 / 235$ & Sight Glass Gaskets @ 503' - 0" level & $\begin{array}{l}\text { From vendor info, asbestos gaskets, see } \\
\text { Brian Berglin. }\end{array}$ \\
\hline 186 & 4621 W/369 & $\begin{array}{l}\text { ARC Chutes have asbestos liners for } \\
131.87 \text { Kv breakers. }\end{array}$ & From vendor info, see Ron Shaffer. \\
\hline 187 & $4717 / 212$ & $\begin{array}{l}\text { Chilled water piping and elbows re- } \\
\text { insulated. }\end{array}$ & No asbestos present, WSCF 98001646. \\
\hline 188 & $4717 / 221$ & $\begin{array}{l}\text { Chilled water piping and elbows re- } \\
\text { insulated. }\end{array}$ & No asbestos present, WSCF 98001646. \\
\hline 189 & $4717 / 244$ & $\begin{array}{l}\text { Chilled water piping and elbows re- } \\
\text { insulated. }\end{array}$ & No asbestos present, WSCF 98001646. \\
\hline 190 & $4717 /$ Roof & RSB roof pads & No asbestos present, WSCF 991000365. \\
\hline 191 & $4717 /$ Roof & RSB extension roof material. & No asbestos present, WSCF 991000365. \\
\hline 192 & $4717 /$ Roof & RSB main roof material. & No asbestos present, WSCF 991000367. \\
\hline
\end{tabular}

ACRONYMS: ACBM - Asbestos-Containing Building Material; HVAC - Heating, Ventilation and Air Conditioning; HEHF - Hanford Environmental Health Foundation; DHX - Dump Heat Exchanger; IVHM - In-vessel Handling Machine; PIC - Person-inCharge; FSF - Fuel Storage Facility. 
HNF-SD-FF-DP-008

Revision 6

Appendix B

Page 16 of 26

\section{APPENDIX B: CURRENT IDENTIFIED ACBM LOCATIONS AND BUILDINGS}

\begin{tabular}{|c|c|c|c|c|}
\hline \multicolumn{5}{|c|}{ CURRENT IDENTIFIED ACBM LOCATIONS AND BUILDINGS } \\
\hline Bldg & Room & Loc & Detailed Location and Identification & $\begin{array}{l}\text { Picture } \\
\text { Number }\end{array}$ \\
\hline \multirow[t]{4}{*}{403} & 916 & 1 & Bridge crane M-900 brake shoes & 147 \\
\hline & 902 & 2 & White cloth cable coating-trace heat & 148 \\
\hline & 903 & 3 & White cloth cable coating-trace heat & 148 \\
\hline & 905 & 4 & White cloth cable coating-trace heat & 148 \\
\hline \multirow[t]{6}{*}{405} & 500 & 1 & Polar crane M-4 brake shoes & 147 \\
\hline & - & 2 & Flammastic coating on cable trays at numerous locations & 93 \\
\hline & - & 3 & Flammastic coating at cable entry to motor control center and panels & 143 \\
\hline & - & 4 & $\begin{array}{l}\text { Asbestos baskets in inert gas cooling piping flanges inside inert cells to be sampled when } \\
\text { accessible }\end{array}$ & 152 \\
\hline & - & 5 & $\begin{array}{l}\text { Fiberous yellow and white cable coating at numerous locations in building for trace heating, } \\
\text { thermocouple and servers environment power wiring-see H4-16061, H4-16062 }\end{array}$ & 148,149 \\
\hline & - & - & CLEM brake shoes (typical brake composite) & 174 \\
\hline \multirow[t]{19}{*}{$408 \mathrm{~A}$} & - & 1 & E-4 530 foot elevation-three light/sight ports, three gaskets each light and sight-Total 18 & $38,39,41$ \\
\hline & - & 2 & E-5 530 foot elcvation-three light/sight ports, three gaskets each light and sight-Total 18 & $38,39,41$ \\
\hline & - & 3 & E-6 530 foot Elevation-three light/sight ports, three gaskets each light and sight-Total 18 & $38,39,41$ \\
\hline & $\therefore$ & 4 & E-7 530 foot elevation-three light/sight ports, three gaskets each light and sight-Total 18 & $38,39,41$ \\
\hline & - & 5 & E-4 530 foot elevation-two manways-gasket ea & 40 \\
\hline & - & 6 & E-5 530 foot elevation-two manways-gasket ea & 40 \\
\hline & - & 7 & E- 6530 foot elevation-two manways-gasket ea & 40 \\
\hline & - & 8 & E-7 530 foot elevation-two manways-gasket ea & 40 \\
\hline & - & 9 & E-4 530 foot elevation-fan/iso gate expansion joint & 28,29 \\
\hline & - & 10 & E-5 530 foot elevation-fan/iso gate expansion joint & 28,29 \\
\hline & $\therefore$ & 11 & E-6 530 foot elevation-fan/iso gate expansion joint & 28,29 \\
\hline & - & 12 & E-7 530 foot elevation-fan/iso gate expansion joint & 28,29 \\
\hline & - & 13 & $\begin{array}{l}\text { Q-1 preheater enclosure } 530 \text { foot elevation-three gaskets-induced draft fan, ventilation fan } \\
\text { and burner drawer }\end{array}$ & $\begin{array}{l}32,34 \\
102,123\end{array}$ \\
\hline & - & 14 & $\begin{array}{l}\text { Q-2 preheater enclosure } 530 \text { foot elevation-three gaskets-induced draft fan, ventilation fan } \\
\text { and burner drawer }\end{array}$ & $\begin{array}{l}32,34,102, \\
123\end{array}$ \\
\hline & - & 15 & $\begin{array}{l}\text { Q-3 Preheater enclosure } 530 \text { foot elevation-three gaskets-induced draft fan, ventilation fan } \\
\text { and bumer drawer }\end{array}$ & $\begin{array}{l}32,34,102 \\
123\end{array}$ \\
\hline & - & 16 & $\begin{array}{l}\text { Q-4 Preheater enclosure } 530 \text { foot elevation-three gaskets-induced draft fan, ventilation fan } \\
\text { and bumer drawer }\end{array}$ & $\begin{array}{l}32,34,102, \\
123\end{array}$ \\
\hline & - & 17 & 530 foot elevation-fuel oil pumps P-80, P-143 black mastic at numerous locations & 27 \\
\hline & - & 18 & Q-1 Preheater outside-economizer retum under insulation-two gaskets & 165 \\
\hline & - & 19 & Q-2 Preheater outside-economizer return under insulation-two gaskets & 165 \\
\hline
\end{tabular}




\begin{tabular}{|c|c|c|c|c|}
\hline \multicolumn{5}{|c|}{ CURRENT IDENTIFIED ACBM LOCATIONS AND BUILDINGS } \\
\hline Bldg & Room & Loc & Detailed Location and Identification & $\begin{array}{l}\text { Picture } \\
\text { Number }\end{array}$ \\
\hline \multirow[t]{31}{*}{$408 \mathrm{~A}$} & - & 20 & Q-3 Preheater outside-economizer return under insulation-two gaskets & 165 \\
\hline & - & 21 & Q-4 Preheater outside-economizer return under insulation-two gaskets & 165 \\
\hline & - & 22 & Q-1 Preheater 545 foot elevation-outlet expansion joint & 164 \\
\hline & - & 23 & Q-2 Preheater 545 foot elevation-outlet expansion joint & 164 \\
\hline & - & 24 & Q-3 Preheater 545 foot elevation-outlet expansion joint & 164 \\
\hline & - & 25 & Q-4 Preheater 545 foot elevation-outlet expansion joint & 164 \\
\hline & - & 26 & E-4 555 foot elevation light/sight viewpoints 10 ports-one gasket port-Total 20 port-Total 20 & $30,44,45$ \\
\hline & - & 27 & E-5 555 foot elevation light/sight viewpoints 10 ports-one gasket port-Total 20 port-Total 20 & $30,44,45$ \\
\hline & + & 28 & E-6 555 foot elevation light/sight viewpoints 10 ports-one gasket port-Total 20 port-Total 20 & $30,44,45$ \\
\hline & - & 29 & E-7555 foot elevation light'sight viewpoints 10 ports-one gasket port-Total 20 port-Total 20 & $30,44,45$ \\
\hline & - & 30 & E-4 555 foot elcvation-manway gasket-header & 139 \\
\hline & - & 31 & E-5 555 foot clevation-manway gasket-header & 139 \\
\hline & - & 32 & E-6 555 foot elevation-manway gasket-header & 139 \\
\hline & - & 33 & E-7555 foot elevation-manway gasket-header & 139 \\
\hline & & 34 & $\begin{array}{l}\text { E-4 } 565 \text { foot elevation-light/sight viewpoints four locations at ladders-three gaskets each port } \\
\text { Total } 24\end{array}$ & 45 \\
\hline & - & 35 & $\begin{array}{l}\text { E-5 } 565 \text { foot elevation-light/sight viewpoints four locations at ladders -three gaskets each } \\
\text { port Total } 24 \text {. }\end{array}$ & 45 \\
\hline & - & 36 & $\begin{array}{l}\text { E-6 } 565 \text { foot elevation-light'sight viewpoints four locations at ladders -three gaskets each } \\
\text { port Total } 24\end{array}$ & 45 \\
\hline & - & 37 & $\begin{array}{l}\text { E-7 } 565 \text { foot elevation-light/sight viewpoints four locations at ladders -three gaskets each } \\
\text { port Total } 24\end{array}$ & 45 \\
\hline & - & 38 & E-4 572 foot elevation-manway gasket-stack & 45 \\
\hline & - & 39 & E-5 572 foot elevation-manway gasket-stack & 139 \\
\hline & - & 40 & E-6 572 foot elevation-manway gasket-stack & 139 \\
\hline & - & 41 & E-7 572 foot elevation-manway gasket-stack & 139 \\
\hline & - & 42 & E-4 570 foot elevation-flat gasket damper assembly to stack-top to bottom & 138 \\
\hline & - & 43 & E-5 570 foot elevation-flat gasket damper assembly to stack top to bottom & 138 \\
\hline & 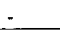 & 44 & E-6 570 foot elevation-flat gasket damper assembly to stack top to bottom & 138 \\
\hline & $\therefore$ & 45 & E-7 570 foot elevation-flat gasket damper assembly to stack-top to bottom & 138 \\
\hline & - & 46 & E-4 570 foot elevation-insulation block at dampers behind metal sheeting & 26 \\
\hline & 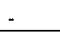 & 47 & E-5 570 foot elevation-insulation block at dampers behind metal sheeting & 26 \\
\hline & - & 48 & E-6 570 foot elevation-insulation block at dampers behind metal sheeting & 26 \\
\hline & - & 49 & E-7 570 foot elevation-insulation block at dampers behind metal sheeting & 26 \\
\hline & - & 50 & 555 foot elevation-west roof E-807 duct black mastic coating (east DHX only) & 36 \\
\hline
\end{tabular}


HNF-SD-FF-DP-008

Revision 6

Appendix B

Page 18 of 26

\begin{tabular}{|c|c|c|c|c|}
\hline \multicolumn{5}{|c|}{ CURRENT IDENTIFIED ACBM LOCATIONS AND BUILDINGS } \\
\hline Bldg & Room & Loc & Detailed Location and Identification & $\begin{array}{l}\text { Picture } \\
\text { Number }\end{array}$ \\
\hline \multirow[t]{3}{*}{$408 \mathrm{~A}$} & - & 51 & 555 foot clevation-north pipe tunnel roof black insulcote on valve 23-V-5135 & 102 \\
\hline & - & 52 & 545 foot elevation-pipe tunnel roof material & 61 \\
\hline & - & 53 & Numerous cable tray locations-yellow fiberous cable coating & 149 \\
\hline \multirow[t]{28}{*}{$408 \mathrm{~B}$} & - & 1 & E-8 530 foot elevation-three light/sight ports-three gaskets each light and sight-Total 18 & $38,39,41$ \\
\hline & - & 2 & E-9 530 foot elevation-three light/sight ports-three gaskets each light and sight-Total 18 & $38,39,41$ \\
\hline & - & 3 & E-10 530 foot elevation-three light/sight ports-three gaskets each light and sight-Total 18 & $38,39,41$ \\
\hline & $\cdot$ & 4 & E-11 530 foot elevation-three light/sight ports-three gaskets each light and sight-Total 18 & $38,39,41$ \\
\hline & - & 5 & E-8 530 foot elevation-two manways-gasket ea & 40 \\
\hline & - & 6 & E-9 530 foot elevation-two manways-gasket ea & 40 \\
\hline & - & 7 & E-10 530 foot elevation-two manways-gasket ea & 40 \\
\hline & - & 8 & E-11 530 foot elevation-two manways-gasket ea & 40 \\
\hline & - & 9 & E-8 530 foot elevation-fan/iso gate expansion joint & 28,29 \\
\hline & - & 10 & E-9 530 foot elevation-fan/iso gate expansion joint & 28,29 \\
\hline & - & 11 & E-10 530 foot elevation-fan/iso gate expansion joint & 28,29 \\
\hline & - & 12 & E- 11530 foot elevation-fan/iso gate expansion joint & 28,29 \\
\hline & $=$ & 13 & $\begin{array}{l}\text { Q-5 preheater enclosure } 530 \text { foot elevation-three gaskets-induced draft fan, ventilation fan } \\
\text { and burner drawer }\end{array}$ & $\begin{array}{l}32,34,102, \\
123\end{array}$ \\
\hline & - & 14 & $\begin{array}{l}\text { Q-6 preheater enclosure } 530 \text { foot elevation-three gaskets-induced draft fan, ventilation fan } \\
\text { and burner drawer }\end{array}$ & $\begin{array}{l}32,34,102, \\
123\end{array}$ \\
\hline & - & 15 & $\begin{array}{l}\text { Q-7 preheater enclosure } 530 \text { foot elevation-three gaskets-induced draft fan, ventilation fan } \\
\text { and burner drawcr }\end{array}$ & $\begin{array}{l}32,34,102 \\
123\end{array}$ \\
\hline & - & 16 & $\begin{array}{l}\text { Q- } 8 \text { preheater enclosure } 530 \text { foot elevation-three gaskets-induced draft fan, ventilation fan } \\
\text { and burner drawer }\end{array}$ & $\begin{array}{l}32,34,102, \\
123\end{array}$ \\
\hline & - & 17 & 530 foot elevation-fuel oil pumps P-81, P- 144 black mastic at numerous locations & 27 \\
\hline & - & 18 & Q-5 preheater outside economizer return under insulation-two gaskets & 165 \\
\hline & - & 19 & Q-6 preheater outside economizer return under insulation-two gaskets & 165 \\
\hline & $\therefore$ & 20 & Q-7 preheater outside economizer return under insulation-two gaskets & 165 \\
\hline & - & 21 & Q-8 prehcater outside economizer return under insulation-two gaskets & 165 \\
\hline & - & 45 & E-11 570 foot elevation-flat gasket-damper assembly to stack top to bottom & 138 \\
\hline & - & 46 & E-8 570 foot elevation-insulation block at dampers behind metal sheeting & 26 \\
\hline & $\cdot$ & 47 & E-9 570 foot elevation-insulation block at dampers behind metal slreeting & 26 \\
\hline & $\because$ & 48 & E-10 570 foot elevation-insulation block at dampers behind metal sheeting & 26 \\
\hline & - & 49 & E-11 570 foot elevation-insulation block at dampers behind metal sheeting & 26 \\
\hline & $\cdot$ & 50 & 555 foot elevation-north pipe tunnel roof black insulcote in vatve $23-\mathrm{V}-5124$ & 102 \\
\hline & - & 51 & 545 foot elevation-pipc roof material & 61 \\
\hline
\end{tabular}

ACRONYMS: $\quad$ ACBM - Asbestos-Containing Building Material; HVAC - Heating, Ventilation and Air Conditioning; HEHF - Hanford Environmental Health Foundation; DHX - Dump Heat Exchanger; IVHM - In-vessel Handling Machine; PIC - Person-inCharge; FSF - Fuel Storage Facility. 
HNF-SD-FF-DP-008

Revision 6

Appendix B

Page 19 of 26

\begin{tabular}{|c|c|c|c|c|}
\hline \multicolumn{5}{|c|}{ CURRENT IDENTIFIED ACBM LOCATIONS AND BUILDINGS } \\
\hline Bldg & Room & Loc & Detailed Location and Identification & $\begin{array}{l}\text { Picture } \\
\text { Number }\end{array}$ \\
\hline \multirow[t]{2}{*}{$408 B$} & - & 52 & Numerous cable tray locations-yellow fiberous cable coating & 149 \\
\hline & - & 53 & Inspection ports-upper & 180,181 \\
\hline \multirow[t]{29}{*}{$408 \mathrm{C}$} & - & 1 & E-12530 foot elevation-one light/sight port-three gaskets each light and sight-Total 18 & $38,39,41$ \\
\hline & - & 2 & E-13 530 foot elevation-one light/sight port-three gaskets each light and sight-Total 18 & $38,39,41$ \\
\hline & - & 3 & E-14 530 foot elevation-one light/sight port-three gaskets each light and sight-Total 18 & $38,39,41$ \\
\hline & - & 4 & E-15 530 foot elevation-one light/sight ports-three gaskets each light and sight-Total 18 & $38,39,41$ \\
\hline & - & 5 & E-12530 foot elevation-two manways-gasket each & 40 \\
\hline & - & 6 & E-13 530 foot elevation-two manways-gasket each & 40 \\
\hline & - & 7 & E-14530 foot elevation-two manways-gasket each & 40 \\
\hline & - & 8 & E-15 530 foot elevation-two manways-gasket each & 40 \\
\hline & - & 9 & E-12 530 foot elevation-fan/iso gate expansion joint & 28,29 \\
\hline & - & 10 & E-13 530 foot elevation-fan/iso gate expansion joint & 28,29 \\
\hline & - & 11 & E-14 530 foot elevation-fan/iso gate expansion joint & 28,29 \\
\hline & - & 12 & E-15 530 foot elevation-fan/iso gate expansion joint & 28,29 \\
\hline & - & 13 & $\begin{array}{l}\text { Q-9 preheater enclosure } 530 \text { foot elevation-two gaskets-induced draft fan, ventilation fan and } \\
\text { burner drawer }\end{array}$ & $\begin{array}{l}31,34,102 \\
123\end{array}$ \\
\hline & - & 14 & $\begin{array}{l}\text { Q-10 preheater enclosure } 530 \text { foot elevation-two gaskets-induced draft fan, ventilation fan } \\
\text { and burner drawer }\end{array}$ & $\begin{array}{l}31,34,102 \\
123\end{array}$ \\
\hline & - & 22 & Q-5 preheater 545 foot elevation-outlet expansion joint & 164 \\
\hline & - & 23 & Q-6 preheater 545 foot elevation-outlet expansion joint & 164 \\
\hline & - & 24 & Q-7 preheater 545 foot elevation-outlet expansion joint & 164 \\
\hline & - & 25 & Q-8 preheater 545 foot elevation-outlet expansion joint & 164 \\
\hline & - & 26 & E-8 555 foot elevation-light/sight viewpoints 10 ports-one gasket port-Total 20 & $30,44,45$ \\
\hline & - & 27 & E-9 555 foot elevation-light/sight viewpoints 10 ports-one gasket port-Total 20 & $30,44,45$ \\
\hline & - & 28 & E-10 555 foot clevation-light/sight viewpoints 10 ports-one gasket port-Total 20 & $30,44,45$ \\
\hline & - & 29 & E-11 555 foot elevation-light/sight viewpoints 10 ports-one gasket port-Total 20 & $30,44,45$ \\
\hline & - & 30 & E-8 555 foot elevation-manway gasket-header & 139 \\
\hline & - & 31 & E-9 $\$ 55$ foot elevation-manway gasket-header & 139 \\
\hline & - & 32 & E-10 555 foot elevation-manway gasket-header & 139 \\
\hline & - & 33 & E-11 555 foot elevation-manway gasket-header & 139 \\
\hline & - & 34 & $\begin{array}{l}\text { E- } 8565 \text { foot elevation-light/sight viewpoints four locations at ladders - three gaskets each } \\
\text { port-Total } 24\end{array}$ & 45 \\
\hline & - & 35 & $\begin{array}{l}\text { E-9 } 565 \text { foot elevation-lightsight viewpoints four locations at ladders-three gaskets each } \\
\text { port-Total } 24\end{array}$ & 45 \\
\hline & - & 36 & $\begin{array}{l}\text { E-10 } 565 \text { foot elevation-light/sight viewpoints four locations at ladders -three gaskets each } \\
\text { port-Total } 24\end{array}$ & 45 \\
\hline
\end{tabular}




\begin{tabular}{|c|c|c|c|c|}
\hline \multicolumn{5}{|c|}{ CURRENT IDENTIFIED ACBM LOCATIONS AND BUILDINGS } \\
\hline Bldg & Room & Loc & Detailed Location and Identification & $\begin{array}{l}\text { Pieture } \\
\text { Number }\end{array}$ \\
\hline \multirow[t]{30}{*}{$408 \mathrm{C}$} & - & 37 & $\begin{array}{l}\text { E-11 } 565 \text { foot elevation-light/sight viewpoints four locations at ladders -three gaskets cach } \\
\text { port-Total } 24 \text {. }\end{array}$ & 45 \\
\hline & - & 38 & E-8 572 foot elevation-manway gasket-stack & 139 \\
\hline & - & 39 & E-9 572 foot elevation-manway gasket-stack & 139 \\
\hline & - & 40 & E-10 572 foot elevation-manway gasket-stack & 139 \\
\hline & - & 41 & E-11 572 foot elevation-manway gasket-stack & 139 \\
\hline & - & 42 & E-8 570 foot elevation-flat gasket-damper assembly to stack-top to bottom & 138 \\
\hline & - & 43 & E-9 570 foot elevation-flat gasket-damper assembly to stack-top to bottom & 138 \\
\hline & - & 44 & E-10 570 foot elevation-flat gasket-damper assembly to stack-top to bottom & 138 \\
\hline & - & 15 & $\begin{array}{l}\text { Q-11 preheater enclosure } 530 \text { foot elevation-two gaskets-induced draft fan, ventilation fan } \\
\text { and burner drawer }\end{array}$ & $\begin{array}{l}31,34,102 \\
123\end{array}$ \\
\hline & - & 16 & $\begin{array}{l}\text { Q-12 preheater enclosure } 530 \text { foot elevation-two gaskets-induced draft fan, ventilation fan } \\
\text { and burner drawer }\end{array}$ & $\begin{array}{l}31,34,102, \\
123\end{array}$ \\
\hline & - & 17 & 530 foot elevation-fuel oil pumps p- $82, p-145$ black mastic at numerous locations & 27 \\
\hline & - & 18 & Q-9 preheater outside-economizer return under insulation-two gaskets & 165 \\
\hline & - & 19 & Q-10 preheater outside-economizer return under insulation-two gaskets & 165 \\
\hline & - & 20 & Q-11 preheater outside-economizer return under insulation-two gaskets & 165 \\
\hline & - & 21 & Q-12 preheater outside-economizer return under insulation-two gaskets & 165 \\
\hline & $\therefore$ & 22 & Q-9 preheater 545 foot elevation-outlet expansion joint & 164 \\
\hline & - & 23 & Q-10 preheater 545 foot elevation-outlet expansion joint & 164 \\
\hline & - & 24 & Q-11 preheater 545 foot elevation-outlet expansion joint & 164 \\
\hline & - & 25 & Q-12 preheater 545 foot elevation-outlet expansion joint & 164 \\
\hline & - & 26 & E-12 555 foot elevation-light/sight viewpoints 10 ports-one gasket port-total 20 & $30,44,45$ \\
\hline & - & 27 & E-13 555 foot elevation-light/sight viewpoints 10 ports-one gasket port-total 20 & $30,44,45$ \\
\hline & $\therefore$ & 28 & E-14 555 foot elevation-light'sight viewpoints 10 ports-one gasket port-total 20 & $30,44,45$ \\
\hline & - & 29 & E-15 555 foot elevation-light/sight viewpoints 10 ports-one gasket port-total 20 & $30,44,45$ \\
\hline & $\therefore$ & 30 & E-12 555 foot elevation-manway gasket-header & 139 \\
\hline & $=$ & 31 & E-13 555 foot elevation-manway gasket-header & 139 \\
\hline & - & 32 & E-14 555 foot elevation-manway gasket-header & 139 \\
\hline & - & 33 & E-15 555 foot elevation-manway gasket-header & 139 \\
\hline & - & 34 & $\begin{array}{l}\text { E-12 } 565 \text { foot elevation-light/sight viewpoints four locations at ladders-three each port-total } \\
24\end{array}$ & 45 \\
\hline & - & 35 & $\begin{array}{l}\text { E-13 } 565 \text { foot elevation-light/sight viewpoints four locations at ladders-three each port-total } \\
24\end{array}$ & 45 \\
\hline & - & 36 & $\begin{array}{l}\text { E-14 } 565 \text { foot elcvation-light/sight viewpoints four locations at ladders -three each port-total } \\
24\end{array}$ & 45 \\
\hline
\end{tabular}




\begin{tabular}{|c|c|c|c|c|}
\hline \multicolumn{5}{|c|}{ CURRENT IDENTIFIED ACBM LOCATIONS AND BUILDINGS } \\
\hline Bldg & Room & Loc & Detailed Location and Identification & $\begin{array}{l}\text { Picture } \\
\text { Number }\end{array}$ \\
\hline \multirow[t]{31}{*}{$408 \mathrm{C}$} & - & 37 & $\begin{array}{l}\text { E-15565 foot elevation-light/sight viewpoints four locations at ladders -three each port-total } \\
24\end{array}$ & 45 \\
\hline & - & 38 & E-12 572 foot elevation-manway gasket-stack & 139 \\
\hline & - & 39 & E-13 572 foot elevation-manway gasket-stack & 139 \\
\hline & - & 40 & E-14572 foot elevation-manway gasket-stack & 139 \\
\hline & - & 41 & E-15 572 foot elevation-manway gasket-stack & 139 \\
\hline & - & 42 & E-12570 foot elevation-flat gasket damper assembly to stack-top to bottom & 138 \\
\hline & - & 43 & E-13 570 foot elevation-flat gasket damper assembly to stack-top to bottom & 138 \\
\hline & - & 44 & E-14570 foot elevation-flat gasket damper assembly to stack-top to bottom & 138 \\
\hline & - & 45 & E-15 570 foot elevation-flat gasket damper assembly to stack-top to bottom & 138 \\
\hline & - & 46 & E-12570 foot elevation-insulation block at dampers behind metal sheeting & 26 \\
\hline & - & 47 & E-13570 foot clevation-insulation block at dampers behind metal sheeting & 26 \\
\hline & - & 48 & E-14570 foot clevation-insulation block at dampers behind metal sheeting & 26 \\
\hline & 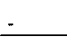 & 49 & E-15 570 foot clevation-insulation block at dampers behind metal sheeting & 26 \\
\hline & - & 50 & 555 foot elevation-north pipe tunnel roof-black insulcote in valve $23-\mathrm{V}-5130$ & 102 \\
\hline & - & 51 & 545 foot elevation-pipe tunnel roof material & 61 \\
\hline & - & 52 & Numerous cable tray locations-yellow fiberous cable coating & 149 \\
\hline & - & 1 & E-76 CLS DHX $\# 2555$ foot elevation-expansion joints at fans of two each & $51,55,57$ \\
\hline & - & 2. & E-74 CLS DHX $\# 2555$ foot elevation-expansion joints at fans of two each & $51,55,57$ \\
\hline & - & 3 & $\begin{array}{l}\text { E-76 CLS DHX \#2 } 555 \text { foot elevation-light/sight viewpoint-two at inlet dampers-three } \\
\text { gaskets cach-Total } 12\end{array}$ & 54,56 \\
\hline & - & 4 & $\begin{array}{l}\text { E-74 CLS DHX } \# 2555 \text { foot elevation-light/sight viewpoint-two at inlet dampers-three } \\
\text { gaskets each-Total } 12\end{array}$ & 54,56 \\
\hline & - & 5 & E-76 CLS DHX \#2 555 foot elevation-manway gasket-west side & 40 \\
\hline & - & 6 & E-74 CLS DHX \#2 555 foot elevation-manway gasket-west side & 40 \\
\hline & - & 7 & E-76 CLS DHX \#2 555 foot elevation-light/sight viewpoint north end-six gaskets & 56 \\
\hline & - & 8 & E-74 CLS DHX \#2 555 foot elevation-light/sight viewpoint north end-six gaskets & 56 \\
\hline & - & 9 & E-76 CLS DHX \#2 555 foot elevation-lighu/sight viewpoint north end-six gaskets & 56 \\
\hline & - & 10 & E-74 CLS DHX\#1 555 foot elevation-light/sight viewpoint four places-24 gaskets & 56 \\
\hline & - & 11 & E-76 CLS DHX \#2565 foot elevation-expansion joints on preheater duct outlet-two each & 58 \\
\hline & - & 12 & E-76 CLS DHX \#1565 foot elevation-expansion joints on preheater duct outlet-two each & 58 \\
\hline & - & 13 & E-76 CLS DHX \#2565 foot elevation-manway gasket-west side & 40 \\
\hline & - & 14 & E-74 CLS DHX \#1 565 foot elevation-manway gasket-west side & 40 \\
\hline & - & 15 & $\begin{array}{l}\text { E-76 CLS DHX \#2 } 580 \text { foot elevation-lightsight viewpoint-two at outlet dampers-three } \\
\text { gaskets each total } 12\end{array}$ & 59,60 \\
\hline
\end{tabular}




\begin{tabular}{|c|c|c|c|c|}
\hline \multicolumn{5}{|c|}{ CURRENT IDENTIFIED ACBM LOCATIONS AND BUILDINGS } \\
\hline Bldg & Room & Loc & Detailed Location and Identification & $\begin{array}{l}\text { Picture } \\
\text { Number }\end{array}$ \\
\hline \multirow[t]{4}{*}{$408 \mathrm{C}$} & - & 16 & $\begin{array}{l}\text { E-74 CLS DHX \#1 } 580 \text { foot clevation-light/sight viewpoint-two at outlet dampers-three } \\
\text { gaskets each total } 12\end{array}$ & 59,60 \\
\hline & - & 17 & E-76 CLS DHX \#2 580 foot elevation-damper/stack gasket & 138 \\
\hline & - & 18 & E-74 CLS DHX $\$ 1580$ foot elevation-damper/stack gasket & 138 \\
\hline & - & 19 & $\begin{array}{l}\text { Numerous locations-yellow coated cable for trace heat in headers and in pipeways-see } \\
\mathrm{H} 4-16061, \mathrm{H} 4-16062\end{array}$ & {$[48,149$} \\
\hline $432 \mathrm{~A}$ & - & & No locations identified & \\
\hline \multirow[t]{2}{*}{436} & - & 1 & East side, outside ductwork coating (repaired) & 120 \\
\hline & - & 2 & East side, outsidc ductwork coating (repaired) & 121 \\
\hline \multirow[t]{3}{*}{437} & - & 1 & SDCV heat trace wire coating-various & 149 \\
\hline & - & 2 & Crane brake shocs-M2003, M2004 & 149 \\
\hline & - & 3 & Fire wall penetration sealant on fire water supply piping & $\lfloor 47$ \\
\hline 481 & - & 1 & No locations identified & 125 \\
\hline $481 \mathrm{~A}$ & - & & Black mastic on piping-small diameter & \\
\hline 483 & - & 1 & 560 foot elevation on roof of interior building-four tanks-black mastic & 151 \\
\hline \multirow[t]{5}{*}{484} & - & 1 & 550 foot elevation & $\begin{array}{l}9,10,11, \\
12,13,14, \\
15\end{array}$ \\
\hline & - & 2 & 550 foot elevation-moisture separator U-479 black mastic coating (repaired) & 8 \\
\hline & - & 3 & 550 foot elevation-moisture separator U-480 black mastic coating & 6 \\
\hline & - & 4 & 550 foot elevation-moisture separator U-605 black mastic coating & 7 \\
\hline & $\therefore$ & 5 & 550 foot clevation-moisture separator U-606 black mastic coating & 8 \\
\hline \multirow[t]{8}{*}{$491 \mathrm{E}$} & 418 & 1 & Y-7, Y-10 liquid rheostat tank-asbestos concrete & 156 \\
\hline & 438 & 2 & White floor tile (SISI cage) & 163 \\
\hline & 327 & 3 & Green floor tile & 161 \\
\hline & - & 4 & Yellow or white fabric coated cable for trace heat-see H4-16061, H4-16062 & 148,149 \\
\hline & - & 5 & Flammastic on cable trays numerous locations & 93 \\
\hline & $\dot{-}$ & 6 & Flammastic at panel entry top-numerous locations & 81 \\
\hline & 465 & 7 & Ductwork on roof black mastic coating & 65 \\
\hline & 465 & 8 & Roof walkway pads & 66 \\
\hline \multirow[t]{4}{*}{4915} & 489 & I & $\begin{array}{l}\text { Flange gaskets in inert gas cooler piping to ductwork in inert cells to be sampled when } \\
\text { accessible }\end{array}$ & 152 \\
\hline & - & 2 & Flammastic on cable trays numerous locations & 93 \\
\hline & - & 3 & Flammastic at panel entry top-mumerous locations & 81 \\
\hline & - & 4 & Yellow or white fabric coated cable for trace heat-see H4-16061, H4-16062 & 148,149 \\
\hline
\end{tabular}

ACRONYMS: ACBM - Asbestos-Containing Building Material; HVAC - Heating, Ventilation and Air Conditioning; HEHF - Hanford Environmental Health Foundation; DHX - Dump Heat Exchanger; IVHM - In-vessel Handling Machine; PIC - Person-inCharge; FSF - Fuel Storage Facility. 
HNF-SD-FF-DP-008

Revision 6

Appendix B

Page 23 of 26

\begin{tabular}{|c|c|c|c|c|}
\hline \multicolumn{5}{|c|}{ CURRENT IDENTIFIED ACBM LOCATIONS AND BUILDINGS } \\
\hline Bldg & Room & Loc & Detailed Location and Identification & $\begin{array}{l}\text { Picture } \\
\text { Number }\end{array}$ \\
\hline $491 S$ & 498 & 5 & Roof walkway pads & 66 \\
\hline \multirow[t]{7}{*}{$491 \mathrm{~W}$} & 429 & 1 & Y-8, Y-1 I liquid rheostat tank-asbestos concrete & 156 \\
\hline & 447 & 2 & Y-9, Y-13 liquid rheostat tank-asbestos concrete & 156 \\
\hline & - & 3 & Flammastic on cable trays numerous locations & 93 \\
\hline & - & 4 & Flammastic at panel entry top-numerous locations & 81 \\
\hline & - & 5 & Yellow or white fabric coated cable for trace heat-see H4-16061, H4- 16062 & 148,149 \\
\hline & 466 & 6 & Roof walkway pads (repaired) & 66 \\
\hline & 466 & 7 & Ductwork on roof black mastic coating (repaired) & 65 \\
\hline \multirow[t]{11}{*}{$4621 E$} & 311 & 1 & Green floor tile & 161 \\
\hline & 312 & 2 & Green floor tile & 161 \\
\hline & 314 & 3 & Cream-white floor tile & 163 \\
\hline & 317 & 4 & Cream-white floor tile & 163 \\
\hline & 319 & 5 & Cream-white floor tile & 163 \\
\hline & 323 & 6 & Cream-white floor tile & 163 \\
\hline & - & 7 & Flammastic on cable trays numerous locations & 93 \\
\hline & $\therefore$ & 8 & Flammatic at panel entry top-numerous locations & 81 \\
\hline & - & 9 & Yellow or white fabric coated cable for trace heat-see H4-16061, H4-16062 & 148,149 \\
\hline & 309 & 10 & Diesel generator $\sharp 1$ exhaust system gaskets & NONE \\
\hline & 340 & 11 & Roof walkway pads (repaired) & 66 \\
\hline \multirow{8}{*}{$\begin{array}{l}4621 \\
W\end{array}$} & - & 1 & Flammastic on cable trays numerous locations & 142 \\
\hline & - & 2 & Flammastic at panel entry top-numerous location & 143 \\
\hline & 366 & 3 & Black mastic on cooling water line at floor in northwest corner-heat trace & 129 \\
\hline & 366 & 4 & $\begin{array}{l}\text { Black mastic on fire water line entering building outside near trace box tag S- } 68 \text {, recovered } \\
11 / 97\end{array}$ & 141 \\
\hline & 380 & 5 & Roof walkway pads (repaired) & 66 \\
\hline & 380 & 6 & Ductwork on roof black mastic coating (repaired) & $65,69,71$ \\
\hline & - & 7 & Yellow or white fabric coated for trace heat-see H4-16061, H4-16062 & 148,149 \\
\hline & 369 & 8 & Arc Chute Asbestos Liner & 186 \\
\hline \multirow[t]{6}{*}{4703} & 121 & 1 & Green floor tile under carpet (repaired) & 161 \\
\hline & 122 & 2 & Green floor tile under carpet (repaired) & 161 \\
\hline & 128 & 3 & Green and white floor tile (161 repaired) & 161,163 \\
\hline & 132 & 4 & Green floor tile under carpet (repaired) & 161 \\
\hline & 135 & 5 & Cream-white floor tile & 163 \\
\hline & 136 & 6 & Cream-white floor tile & 158 \\
\hline
\end{tabular}

ACRONXMS: $\quad$ ACBM - Asbestos-Containing Building Material; HVAC - Heating, Ventilation and Air Conditioning; HEHF - Hanford Environmental Health Foundation; DHX - Dump Heat Exchanger; IVHM - In-vessel Handling Machine; PIC - Person-inCharge; FSF - Fuel Storage Facility. 
HNF-SD-FF-DP-008

Revision 6

Appendix B

Page 24 of 26

\begin{tabular}{|c|c|c|c|c|}
\hline \multicolumn{5}{|c|}{ CURRENT IDENTIFIED ACBM LOCATIONS AND BUILDINGS } \\
\hline Bldg & Room & Loc & Detailed Location and Identification & $\begin{array}{l}\text { Picture } \\
\text { Number }\end{array}$ \\
\hline \multirow[t]{8}{*}{4703} & 138 & 7 & Cream-white floor tile & 163 \\
\hline & 139 & 8 & Cream-white floor tile & 163 \\
\hline & 140 & 9 & Cream-white floor tile & 163 \\
\hline & - & 10 & Flammastic on cable trays numerous locations & 93,142 \\
\hline & - & 11 & Flammastic at panel entry top-numerous locations & 143 \\
\hline & 104 & & Chilled water line 1-1/2" elbow (no asbestos present, w961002468) & 176 \\
\hline & 254 & & Chilled water line 4" elbow (no asbestos present, W961002469) & 177 \\
\hline & 136 & -- & Before and after-control room floor (see picture no. 158) & 175 \\
\hline 4710 & & & None identified & \\
\hline $4713 \mathrm{~A}$ & - & 1 & Floor tile mastic. & 154 \\
\hline $4713 \mathrm{~B}$ & & & Resistive load banks (five total) - three changed out and two tagged asbestos containing. & 182 \\
\hline $4713 \mathrm{C}$ & & & None identified & \\
\hline \multirow[t]{3}{*}{$47 \dot{13} \mathrm{D}$} & - & 1 & HVAC ducts at heater unit- 550 foot elevation (repaired) & 1,2 \\
\hline & & 2 & Ductwork on roof black mastic coating (repaired) & 3,4 \\
\hline & & 3 & Green floor tile in manipulator shop & 50 \\
\hline 4716 & & & None identified & \\
\hline \multirow[t]{15}{*}{4717} & 258 & 1 & Black mastic on top of T-13A chilled water surge tank-east side & 104 \\
\hline & 258 & 2 & Black mastic on top of $\mathrm{T}-13 \mathrm{~B}$ chilled water surge tank-east side & 105 \\
\hline & 258 & 3 & T-194 insulation tower $\# 2$ & 109 \\
\hline & - & 4 & Roof walkway pads (repaired) & 66 \\
\hline & 220 & 5 & Yellow or white fabric coated cable for trace heat-see H4-16061, H4-16062 & 148,149 \\
\hline & - & 6 & Flanmastic on cable trays numerous locations & 142 \\
\hline & $\cdot$ & 7 & Flammastic at panel entry top-numerous locations & 143 \\
\hline & 258 & 54 & R189 Compressor Ist stage upper gasket to be changed-assumed ACBM & 178 \\
\hline & 235 & 8 & Sign Glass Gasket at 530'-0" level. & 185 \\
\hline & 212 & 9 & Chilled water piping and elbow re-insulated. & 187 \\
\hline & 221 & 10 & Chilled water piping and elbow re-insulated. & 188 \\
\hline & 244 & 11 & Chilled water piping and elbow re-insulated. & 189 \\
\hline & Roof & 12 & RSB roof pads. & 190 \\
\hline & Roof & 13 & RSB extension roof material. & 191 \\
\hline & Roof & 14 & RSB main roof material. & 192 \\
\hline 4721 & - & 1 & Gas turbine exhaust flanges and cabinet doors & NONE \\
\hline 4842 & - & 1 & Molding at door & 166 \\
\hline
\end{tabular}

ACRONYMS: ACBM - Asbestos-Containing Butlding Material; HVAC - Heating, Ventilation and Air Conditioning; HEHF - Hanford Environmental Health Foundation; DHX - Dump Heat Exchanger; IVHM - In-vessel Handling Machine; PIC - Person-inCharge; FSF - Fuel Storage Facility. 
HNF-SD-FF-DP-008

Revision 6

Appendix B

Page 25 of 26

\begin{tabular}{|l|l|l|l|l|l|}
\hline \multicolumn{3}{|c|}{ CURRENT IDENTIFIED ACBM LOCATIONS AND BUILDINGS } \\
\hline Bldg & Room & Loc & Detailed Location and Identification & $\begin{array}{l}\text { Picture } \\
\text { Number }\end{array}$ \\
\hline $\begin{array}{l}\text { OUT } \\
\text { SIDE }\end{array}$ & & 1 & $\begin{array}{l}\text { Outside 491E at CON FTT margins equipment U-781A, U-781C-black paper and white } \\
\text { powder }\end{array}$ & 47,48 \\
\cline { 2 - 6 } & & 2 & Valve box east of cooling towers-coated (fixed) & 157 \\
\hline
\end{tabular}


HNF-SD-FF-DP-008

Revision 6

Appendix C

Page 26 of 26

\section{APPENDIX C: CURRENT IDENTIFIED FRIABLE ACBM LOCATIONS BY BUILDING}

\begin{tabular}{|c|c|c|c|c|}
\hline \multicolumn{5}{|c|}{ Current Identified Friable ACBM Locations by Building for Annual Inspection } \\
\hline Bldg \# & Room & Loc & Identification & Pic/Item \# \\
\hline \multirow[t]{2}{*}{$4621-W$} & 365 & 1 & Flammastic on cable trays at BN01N5 by B 90 & 142 \\
\hline & 380 & 6 & HVAC on roofs (fixed) 11-93 & $65,69,71$ \\
\hline 4703 & 108 & 10 & Flammastic on cable trays at hanger 108-1-02 & 93 \\
\hline \multicolumn{5}{|c|}{$\begin{array}{l}\text { Note: These cable tray locations are only two as sampled, Flammastic on cable tray are } \\
\text { throughout the plant from the } 489 \text { foot level to the } 570 \text { foot level. }\end{array}$} \\
\hline \multirow{2}{*}{$\begin{array}{l}491- \\
\mathrm{E} \& W\end{array}$} & 465 & 8 & HVAC ducts on roof near E615 (fixed) 11-93 & 65 \\
\hline & 466 & 6 & HVAC ducts on roof near E615 (fixed) 11-93 & 65 \\
\hline \multicolumn{5}{|c|}{$\begin{array}{l}\text { Note: These HVAC duct are located on most roofs at FFTF. Elements have cracked the outer } \\
\text { black coating and exposed the white inner asbestos covering. }\end{array}$} \\
\hline 436 & - & 33 & $\begin{array}{l}\text { Outside, black insulation on ducts, east side of } \\
\text { building (fixed) 11-93 }\end{array}$ & 120,121 \\
\hline $\begin{array}{l}408 \\
\mathrm{ABC}\end{array}$ & $\begin{array}{l}\text { All } \\
\text { DHXs }\end{array}$ & 53 & $\begin{array}{l}\text { The only access door gasket in the DHXs that has } \\
\text { been changed to a new non-asbestos gasket is E- } 8 \\
\text { in the South DHX, all others must be treated as } \\
\text { ACBM. }\end{array}$ & 180,181 \\
\hline
\end{tabular}

